\title{
AN ACTUARIAL APPROACH TO ASSESSING PERSONAL INJURY COMPENSATIONS IN SINGAPORE: THEORY AND PRACTICE
}

\author{
FELIX W.H. CHAN* ${ }^{*}$, WAI-SUM CHAN ${ }^{\ddagger}$ and JOHNNY S.H. LI ${ }^{\S}$ \\ ${ }^{*}$ Faculty of Law \\ The University of Hong Kong \\ Pokfulam Road, Hong Kong \\ fwhchan@hku.hk. \\ $\ddagger$ Department of Finance \\ The Chinese University of Hong Kong \\ Shatin, N.T., Hong Kong \\ chanws@cuhk.edu.hk. \\ $\S$ Department of Statistics and Actuarial Science \\ The University of Waterloo \\ Ontario, Canada N2L3G1 \\ shli@uwaterloo.ca.
}

In Singapore personal injury litigations, successful claimants usually receive their compensations as a lump sum. The main advantage of a lump sum payment is that the proceedings can be concluded with a 'clean break' between the parties. The lump sum is a result of discounting the future pecuniary values into a single present-day amount, considering the time value of money and the claimant's mortality. Conventionally, lump sum awards are determined by making reference to a spread of amounts in comparable cases. However, a fairer method would be one that involves input from not only lawyers but also other experts including economists and actuaries. This study, which is carried out by an inter-professional working group, provides a set of actuarially computed tables for use in personal injury settlements in Singapore. The calculations involve a consideration of recent advancements in stochastic mortality modeling and an empirical study on the econometrics of real returns on risk-free assets in Singapore. We then present two recent personal injury cases in Singapore, aiming at helping the Singapore legal profession understand and use the economic principles with actuarial tables, and educating economists and actuaries the legal concerns and concepts in personal injury cases.

Keywords: Actuarial evidence; Mortality projection; Multipliers; Ogden Tables

JEL Classification: K13, C53 


\section{Introduction}

When an innocent party is injured in a tort-based system of law as the result of the wrong of another party, the innocent party should be awarded adequate and proper compensation. The basic principle underlying the assessment of the quantum of damages is restitutio in integrum, which implies that the amount of compensation awarded should put the successful plaintiff in the position he or she would have been had the tortious action not been committed.

When assessing future pecuniary loss in personal injury litigations, courts often use the multiplicand/multiplier approach. The objective is to calculate a lump sum to compensate the plaintiff for future loss of earnings and to cover a stream of future expenses. This lump sum is simply considered as the product of a multiplicand and a multiplier. The multiplicand (the future annual loss of income and the annual consequential expense, such as the cost of care) is established by evidence put before the judge, who then has to decide an appropriate multiplier. The multiplier is used to discount the future pecuniary values into a present lump sum, considering the time value of money, the plaintiff's mortality and contingencies other than mortality.

The conventional approach to selecting multipliers is based on the applied wisdom of the courts over many years. In choosing a particular multiplier, the court will make comparisons with multipliers used in similar cases. However, when the conventional approach is used, the multipliers would not be linked to the mortality experience or the local economic environment. Furthermore, it is practically impossible to find any truly comparable cases that have similar factors in respect of age and sex of the victims, mortality experience of the general population, inflation, taxation, and investment return rates. The fairness of conventional multipliers, which are based on analogy is, therefore, questionable.

Alternatively, an actuarial approach may be used in deciding a multiplier. In England, the Ogden Tables ${ }^{1}$ - tables of actuarially computed multipliers - assist in the calculation of damages for personal injury. They are computed on the basis of the actuarial equivalence principle, by which we mean the compensating amount is the expected present value of all future losses and expenses. Initially, the Ogden Tables had no legal authority. However, the working party responsible for their production strongly encouraged the legal profession and the judiciary to use them. Although they have been widely used by judges since 1984, they have only recently received formal recognition. Under the Civil Evidence Act 1995, the Ogden Tables are admissible in evidence for the purpose of assessing, in an action for personal injury, the sum to be awarded as general damages for future pecuniary loss. In July 1998 the House of Lords approved actuarial evidence as the primary method of assessing future pecuniary loss, rather than viewing it as a mere check.

At present, courts in Singapore use the conventional approach to choosing multipliers, without admitting any actuarial evidence. However, given that the judicial system in Singapore is based on the English common law, the current practice in Singapore may need to be reformed. Although judicial decisions in the United Kingdom are not binding in the Singapore Courts, these decisions are, even following the introduction of the Application of English Law Act

\footnotetext{
${ }^{1}$ Their first edition, officially named 'Actuarial Tables with Explanatory Notes for Use in Personal Injury and Fatal Accident Cases,' prepared by the British Government Actuary's Department, was published in 1984. They are generally known as the 'Ogden Tables,' after Sir Michael Ogden, QC, who was responsible for their publication, and who was also the chairperson of the joint working party of actuaries and lawyers responsible for victim compensations.
} 
in $1993,{ }^{2}$ still persuasive. The implications of the House of Lords' (July 1998) decision in Singapore cannot yet be seen, but it is anticipated that the conventional approach to choosing multipliers in Singapore will be hotly contested and challenged.

There are several possible ways of implementing the actuarial approach in Singapore. One option is simply to adopt the Ogden Tables in Singapore. However, it would not be practical as the Ogden Tables were constructed in the light of circumstances in England, ${ }^{3}$ but not Singapore. In Figure 1 we compare the 5-year (2001-2005) average values of death probabilities $\left(q_{x}\right)$ for these two regions. ${ }^{4}$ We observe that Singaporeans in general have a lighter mortality pattern (except at a few ages). As a result, the appropriate multipliers for Singaporeans should be larger than those given in the Ogden Tables.

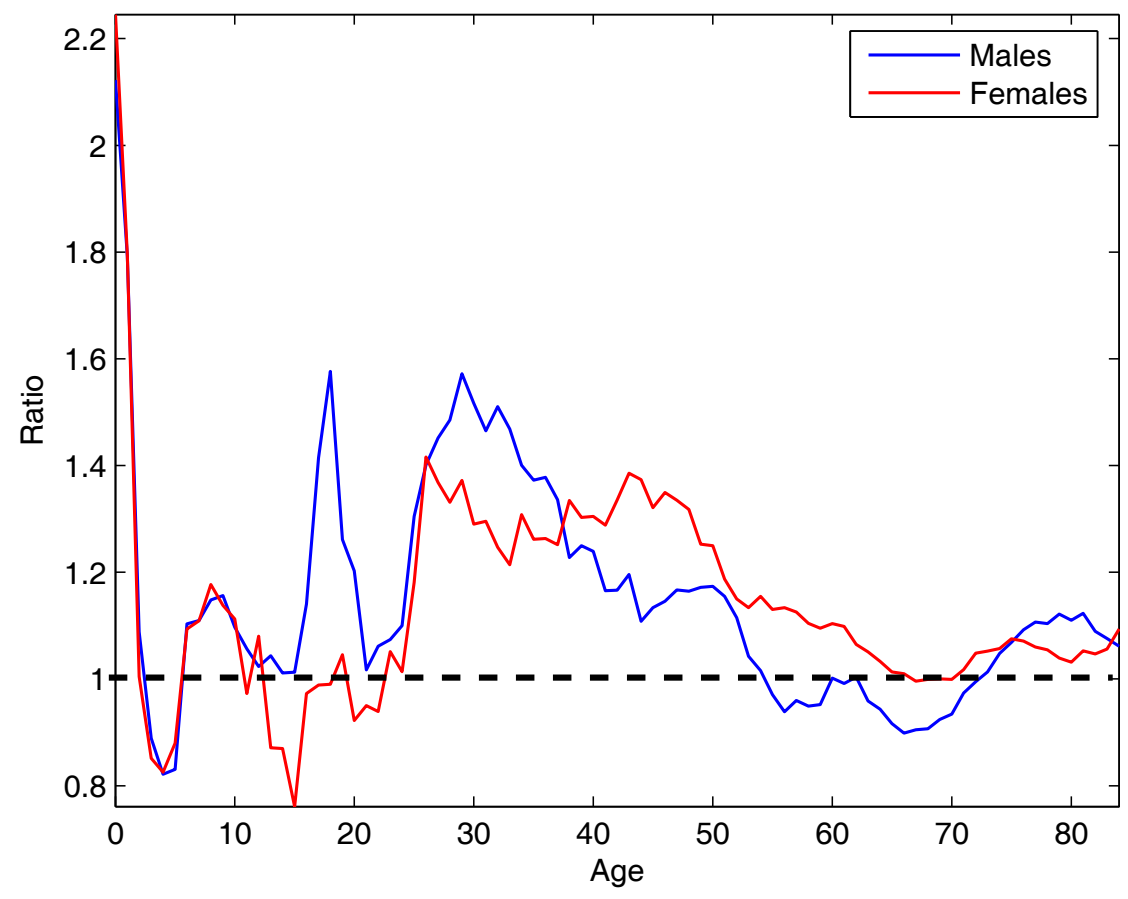

Figure 1. Ratios of death probabilities: England and Wales to Singapore

Another option is to, as recommended by Chan and Chan (2000) in a case commentary, construct modified forms of the Ogden Tables by a working party, which would ideally consist of lawyers, actuaries and econometricians. In the wake of this recommendation, this interdisciplinary study sets out to derive a set of multiplier tables that would be appropriate for

\footnotetext{
${ }^{2}$ Cap 7A, 1994 (Rev Ed). The Act has created a climate in which the Singapore courts have been encouraged to look beyond English decisions when deciding on applicable law. This contrasts strongly with the previous position, under which decisions of the House of Lords relating to very similar areas of law were followed almost automatically by the Singapore courts.

${ }^{3}$ The Ogden Tables are now in their sixth edition. They are calculated using the projected mortality rates for England and Wales assumed in the latest 2002-based population projections.

${ }^{4}$ Sources of data: (i) Human Mortality Database (for England and Wales) and (ii) Singapore Department of Statistics (for Singapore).
} 
use in personal injury cases in Singapore. The derivation requires a reasonable estimate of the future mortality likely to be experienced by the population of Singapore. We obtain such an estimate by considering the stochastic mortality models proposed by Lee and Carter (1992) and Renshaw and Haberman (2006). Further, we examine on the basis of these models the potential impact of cohort effects on the multipliers. The resulting multiplier tables are applied to two recent personal injury cases in Singapore. We intent to, through the study of these cases, help the Singapore legal profession understand and use the actuarial tables and educate actuaries the legal concerns and concepts in personal injury cases.

The remainder of this paper is organized as follows: Section 2 provides an overview of the multiplier tables and explains the underlying actuarial principles; Section 3 details the projection of Singaporeans' mortality and examines the potential impact of cohort effects on the multipliers; Section 4 discusses how an appropriate discount rate may be chosen; Section 5 applies the multiplier tables to some recent personal injury cases in Singapore and compares the actuarial approach (implemented with the multipliers we derived) with the conventional approach; finally, Section 6 concludes.

\section{The Multiplier Tables}

The multipliers in the Ogden Tables allow users to assess the present capital value of future annual loss or expense calculated on the basis of various assumptions. In the current (sixth) edition, there are 28 tables of multipliers, which may be divided into the following categories:

\section{Multipliers for pecuniary loss for life (Multiplier Tables 1 and 2)}

Multiplier Tables 1 and 2 assume that the loss or expense begins immediately and continues for the whole of the rest of the claimant's life, allowing for different potential lifespans, including the possibility of early death or prolonged life.

2. Multipliers for loss of earnings to pension age (Multiplier Tables 3 to 14)

Multipliers Tables 3 to 14 assume that the loss or expense begins without delay but continues only until the claimant's retirement or earlier death. Retirement ages $50,55, \ldots$, 75 are assumed. If the claimant's retiring age is different from that assumed in any of the tables, a linear interpolation may be used. ${ }^{5}$ For instance, if a claimant of age 42 $(x=42)$ is retiring at age $58(R=58)$, then the correct multiplier can be computed by the interpolating between the multipliers for $(x=39, R=55)$ and $(x=44, R=60)$.

3. Multipliers for loss of pension commencing from the retirement age (Multiplier Tables 15 to 26)

Multipliers Tables 15 to 26 assume that the annual loss or annual expense will not begin until the claimant reaches his/her retirement but will then continue for the whole of the rest of his/her life. Due allowance is made for the chance that the claimant may not live to the age of retirement. Retirement ages $50,55, \ldots, 75$ are assumed. An approximation is also required when the claimant's retiring age is different from that assumed in the tables.

\footnotetext{
${ }^{5}$ Within a reasonable number of tables, it is impossible to cover all possible situations. Therefore, approximation techniques may be used even if a more accurate formulation may be available.
} 


\section{Discount factors for term certain (Multiplier Table 27)}

Multiplier Table 27 contains discount factors computed on the basis of a fixed interest rate and a fixed term.

5. Multipliers for pecuniary loss for term certain (Multiplier Table 28)

Multiplier Table 28 contains annuity factors that relate purely to the effect of compound interest and ignore mortality. These factors are used when there is clear evidence to support the view that the claimant is atypical and will enjoy a longer or shorter expectation of life. In this situation, we may approximate the multiplier by an annuity factor (from Multiplier Table 28) whose term equals the claimant's expected future lifetime, determined by the court or agreed by both parties. ${ }^{6}$

In each table, the multipliers/factors are shown for a range of possible annual rates of return ranging from $0 \%$ to $5 \%$. A summary of the Ogden Tables is provided in Table $1 .^{6}$

Table 1. A Summary of the Ogden Tables

\begin{tabular}{|c|c|c|}
\hline Table number & Multipliers & Formula \\
\hline 1,2 & Multipliers for pecuniary loss for life & $\bar{a}_{x}$ \\
\hline 3,4 & Multipliers for loss of earnings to pension age 50 & $\bar{a}_{x: \overline{50-x}\rceil}$ \\
\hline 5,6 & Multipliers for loss of earnings to pension age 55 & $\bar{a}_{x: \overline{55-x}}$ \\
\hline 7,8 & Multipliers for loss of earnings to pension age 60 & $\bar{a}_{x: \overline{60-x}\rceil}$ \\
\hline 9,10 & Multipliers for loss of earnings to pension age 65 & $\bar{a}_{x: \overline{65-x}}$ \\
\hline 11,12 & Multipliers for loss of earnings to pension age 70 & $\bar{a}_{x: \overline{70-x}}$ \\
\hline 13,14 & Multipliers for loss of earnings to pension age 75 & $\bar{a}_{x: \overline{75-x}]}$ \\
\hline 15,16 & Multipliers for loss of pension commercing age 50 & $(50-x) \mid \bar{a}_{x}$ \\
\hline 17,18 & Multipliers for loss of pension commercing age 55 & $(55-x) \mid \bar{a}_{x}$ \\
\hline 19,20 & Multipliers for loss of pension commercing age 60 & $(60-x) \mid \bar{a}_{x}$ \\
\hline 21,22 & Multipliers for loss of pension commercing age 65 & $(65-x) \mid \bar{a}_{x}$ \\
\hline 23,24 & Multipliers for loss of pension commercing age 70 & $(70-x) \mid \bar{a}_{x}$ \\
\hline 25,26 & Multipliers for loss of pension commercing age 75 & $(75-x) \mid \bar{a}_{x}$ \\
\hline 27 & Discounting factors for term certain & $v^{n}$ \\
\hline 28 & Multipliers for pecuniary loss for term certain & $\bar{a}_{\bar{n}\rceil}$ \\
\hline
\end{tabular}

The actuarial approach to assessing personal injury compensations involves the following steps:

1. Choose the appropriate tables

Choose the table that relates to the sex of the plaintiff and the appropriate period of losses and expenses.

\footnotetext{
${ }^{6}$ Note: (i) Multiplier Tables 1, 3, .., 25 are for males while Multiplier Tables 2, 4, .., 26 are for females; (ii) $x$ denotes the age at date of trial.
} 


\section{Choose the appropriate discount rate}

The discount rate is the rate of return that the claimant can be expected to achieve on the lump sum of award before it is used up. The annual rate of return currently to be applied in England is 2.5\% (net of tax), as fixed by the Lord Chancellor on 25 June 2001, and reassessed on 27 July 2001, under the provisions of the Damage Act 1996 Section 1. We will revisit this issue in Section 4.

\section{Locate the appropriate multiplier}

In the appropriate table, find the multiplier given the claimant's age-at-trial and the discount rate chosen.

\section{Adjust the multiplier to incorporate contingencies other than mortality}

The baseline multipliers take no account of risks other than mortality, for example, future redundancy and subsequent unemployment, temporary ill health, permanent disability, and early retirement. The baseline multipliers are adjusted downwards to take account of non-mortality risks, expressed as reduction factors. These reduction factors, which are based on the work of Butt et al. (2008), are provided in the Explanatory Notes of the sixth edition of the Ogden Tables.

\section{Compute the lump sum}

The lump sum award is the product of the multiplier and the multiplicand, which represents the annual loss of earnings and other benefits assessed at the date of trial.

\section{Constructing Multiplier Tables for Singaporeans}

Mortality assumptions are required in constructing multiplier tables for use in personal injury litigations. The basic principle of setting such assumptions is that the multiplier tables should be based on a reasonable estimate of the future mortality likely to be experienced by average members of the population alive today. Multiplier Tables 1 to 26 in the current (sixth) edition of the Ogden Tables show the multipliers which result from the application of projected mortality rates derived from the 2004-based population projection for the United Kingdom. ${ }^{7}$

However, official projections of Singaporeans' mortality are not available. Although Chia and Tsui (2003) made a mortality projection for Singaporeans in their study on retirement income adequacy, the projection they made are for people who are aged 60 or above. Given that the actuarial multipliers involve not only the elderly population, we require a complete and

\footnotetext{
${ }^{7}$ In previous editions, tables have been included based on the mortality rates experienced in England and Wales in a historical three-year period. For example, tables based on mortality experienced in years 1990 to 1992 , published by the Government Actuarys Department as English Life Table No. 15 (ELT15), were set out in the 4th Edition of the tables. However, the Ogden Working Party has decided that it is not necessary to publish these historic tables again in this edition and have correspondingly agreed that the tables to be published should be based on a reasonable estimate of the future mortality likely to be experienced by average members of the population alive today.
} 
up-to-date mortality projection to construct the multiplier tables for Singaporeans.

\subsection{The Data}

We base our mortality projections on the data provided by the Department of Statistics (DOS) of the Singaporean government. The mortality data cover a period of 27 calendar years from 1980 to $2006 .{ }^{8}$ A limitation of the data is that they are given in an abridged form, by which we mean they are provided by age group rather than single age. In more detail, we are given the death probabilities for age 0 , age groups $1-4,5-9,10-14, \ldots, 80-84$ and the open age group $85+$. We take the following steps to obtain single-year death probabilities, which are required in constructing the multiplier tables:

1. For each year, we create from the abridged death rates a hypothetical cohort (i.e., $l_{x}$ for $x=1,5,10, \ldots, 85$, where $l_{x}$ is the number of survivors at age $x$ ) with an arbitrary radix $l_{0}$. Given the hypothetical cohort, we compute the death count for each age group.

2. We disaggregate the lumped death counts by using the method proposed by Boot et al. (1967).

3. From the disaggregated death counts, we can conveniently compute the number of survivors $l_{x}$ and the death probability $q_{x}$ for every single age from 0 to 85 .

4. Following the suggestion of $\mathrm{Li}$ and Chan (2004), we extrapolate projected values of $q_{x}$ to $x=110$ by the Coale-Kisker method (Coale and Kisker, 1990).

\subsection{The Models}

Projections of Singaporeans' future mortality can be made scientifically by using stochastic mortality models. Various stochastic models have been developed in recent years. In this paper, we consider the Lee-Carter model (Lee and Carter, 1992) and its cohort-based extension (Renshaw and Haberman, 2006). These models are widely discussed in the actuarial literature (see, e.g., Lee (2000), Renshaw and Haberman (2003a,b)), and are found to give a good fit to the mortality data of various developed countries (see, e.g., Tuljapurkar et al., 2000).

The Lee-Carter framework specifies the log of the single-year central death rate $\left(m_{x, t}\right)$ at age $x$ and time $t$ as follows:

$$
\ln \left(m_{x, t}\right)=a_{x}+b_{x} k_{t}+\epsilon_{x, t},
$$

where $a_{x}$ is an age-specific parameter that indicates the average level of $\ln \left(m_{x, t}\right)$ over time, $b_{x}$ is another age-specific parameter that measures the sensitivity of $\ln \left(m_{x, t}\right)$ to changes in the mortality index $k_{t}$; and $\epsilon_{x, t}$ is the error term that captures all remaining variations and shows no long-term trend.

As suggested by Wilmoth (1993) and Brouhns et al. (2002), we can assume that the observed death count at any age and in any year is a realization of a Poisson distribution with mean equal

\footnotetext{
${ }^{8}$ The data for year 2006 are preliminary.
} 
to the expected number of deaths under the Lee-Carter model. Given this assumption, the loglikelihood is as follows:

$$
\sum_{x, t}\left(D_{x, t}\left(a_{x}+b_{x} k_{t}\right)-E_{x, t}\left(\exp \left(a_{x}+b_{x} k_{t}\right)\right)+c\right.
$$

where $D_{x, t}$ and $E_{x, t}$ are the number of deaths and exposures at age $x$ and time $t$, respectively, and $c$ is a constant that is free of the model parameters. We obtain the number of exposures by setting $E_{x, t}$ to $\left(l_{x, t}+l_{x, t+1}\right) / 2$, where $l_{x, t}$ is the number of survivors at age $x$ and time $t$, assuming that deaths are uniformly distributed over each year. ${ }^{9}$ By maximizing the log-likelihood using standard Newton's method, we obtain estimates of $\left\{a_{x}\right\},\left\{b_{x}\right\}$, and $\left\{k_{t}\right\}$, which are shown in Figure 2.

The prediction of future death rates is often complicated by cohort effects, which refers to the situation when the mortality improvement for a group of birth years is systematically higher or lower than that of the neighboring cohorts. The implications of cohort effects are twofolds:

1. multipliers for birth cohorts with a systematically higher (lower) rate of mortality improvement are higher (lower), assuming all other factors are equal;

2. the original Lee-Carter model, which specifies no relationship between death rates and years of birth, may not give an adequate fit.

To have a better understanding on cohort effects in Singaporeans' mortality, we consider Renshaw and Haberman's (2006) extension to the original Lee-Carter model. This extension, which relates future death rates $\left(m_{x, t}\right)$ to years of birth $(t-x)$, can be expressed as follows:

$$
\ln \left(m_{x, t}\right)=a_{x}+b_{x} k_{t}+c_{x} \iota_{t-x}+\epsilon_{x, t},
$$

where $a_{x}, b_{x}$, and $k_{t}$ are the original Lee-Carter parameters, $\iota_{t-x}$ is an additional driving force of mortality improvement due to cohort effect, $c_{x}$ determines the sensitivity to $\iota_{t-x}$ at different ages, and $\epsilon_{x, t}$ is the error term. Assuming again that the observed death count at any age and in any time is a realization of a Poisson distribution, we have the following log-likelihood:

$$
\sum_{x, t}\left(D_{x, t}\left(a_{x}+b_{x} k_{t}+c_{x} \iota_{t-x}\right)-E_{x, t}\left(\exp \left(a_{x}+b_{x} k_{t}+c_{x} \iota_{t-x}\right)\right)+c\right.
$$

where $c$ is a constant that is free of the model parameters. Maximizing the log-likelihood above yields estimates of $a_{x}, b_{x}, k_{t}, c_{x}$, and $\iota_{t-x}$. In Figure 3 we show the maximum likelihood estimates of $c_{x}$ and $\iota_{t-x}$. Estimates of $a_{x}, b_{x}$, and $k_{t}$ are similar to those from the original Lee-Carter specification.

We perform a likelihood-ratio test to examine whether or not cohort effects are significant in Singaporeans' mortality. The $p$-values are 0.1625 and 0.5516 for males and females, respectively. These $p$-values indicate that there is not sufficient statistical evidence for cohort effects.

\footnotetext{
${ }^{9}$ Alternatively, we may modify the original Lee-Carter specification when we are given values of $l_{x, t}$ but not $E_{x, t}$. In more detail, we may rewrite the model in a logit scale, i.e., $\ln \left[q_{x, t} /\left(1-q_{x, t}\right)\right]=a_{x}+b_{x} k_{t}+\epsilon_{x, t}$ and assume that $D_{x, t}$ follows a binomial distribution with parameters $l_{x, t}$ and $q_{x, t}$ (see Cosette et al. (2007)).
} 

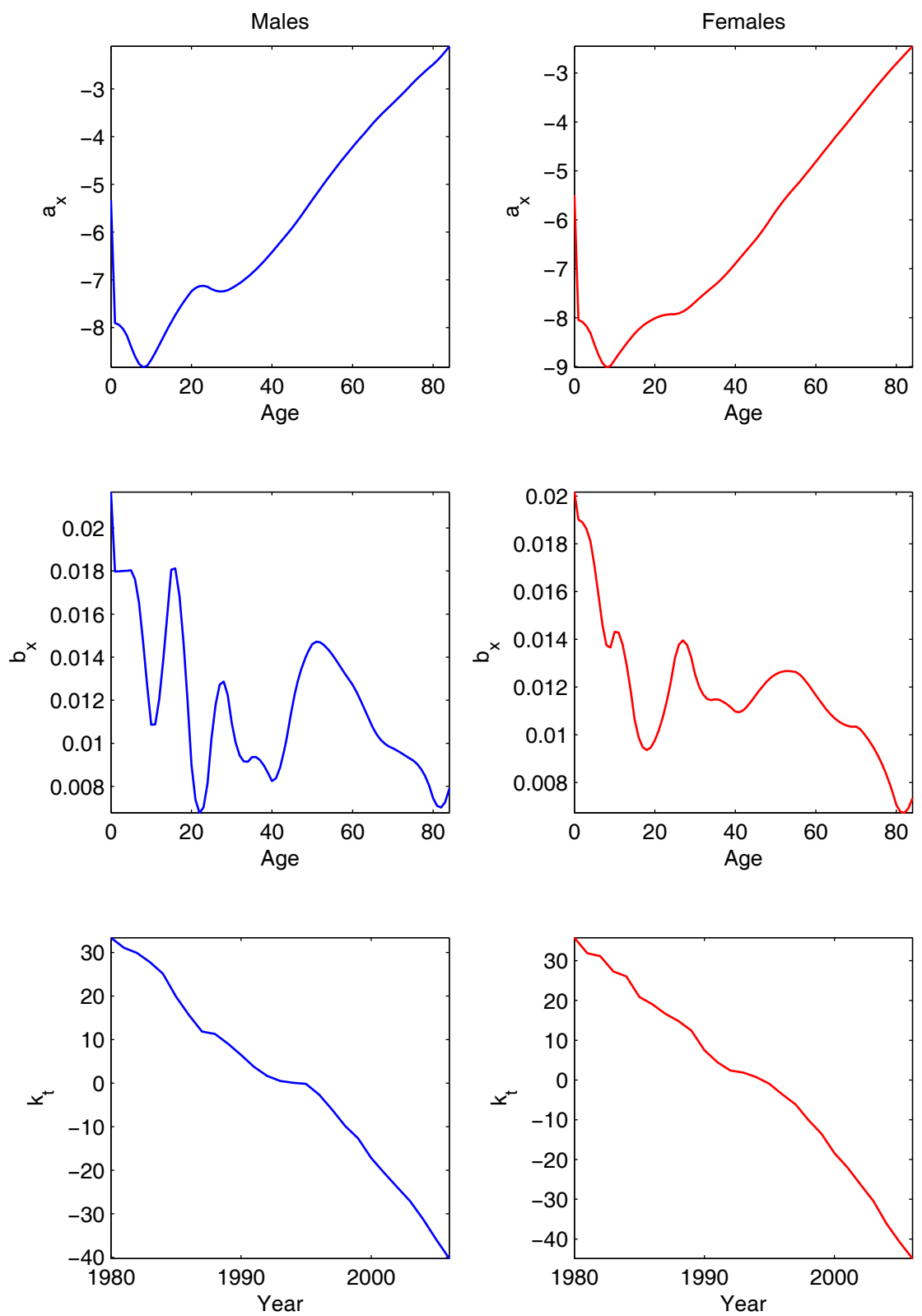

Figure 2. Maximum Likelihood Estimates of the Lee-Carter Parameters

In Table 2 we compare the original Lee-Carter model with its cohort-based extension using the following selection criteria:

1. Akaike Information Criterion (AIC) (Akaike, 1974), defined by $l-j$, where $l$ is the $\log$ likelihood and $j$ is the number of parameters. A higher value of AIC is more preferable.

2. Schwarz-Bayes Criterion (SBC) (Schwarz, 1978), defined by $l-0.5 j \ln (n)$, where $n$ is the number of observations. A higher value of SBC is more preferable.

By the principle of parsimony, we should make use of the least possible number of parameters for adequate representations. The above selection criteria, which have taken account of 
the number of parameters, indicate that the original Lee-Carter model is adequate for modeling Singaporeans' mortality. Therefore, we base the construction of multipliers on mortality projections from the original Lee-Carter specification.
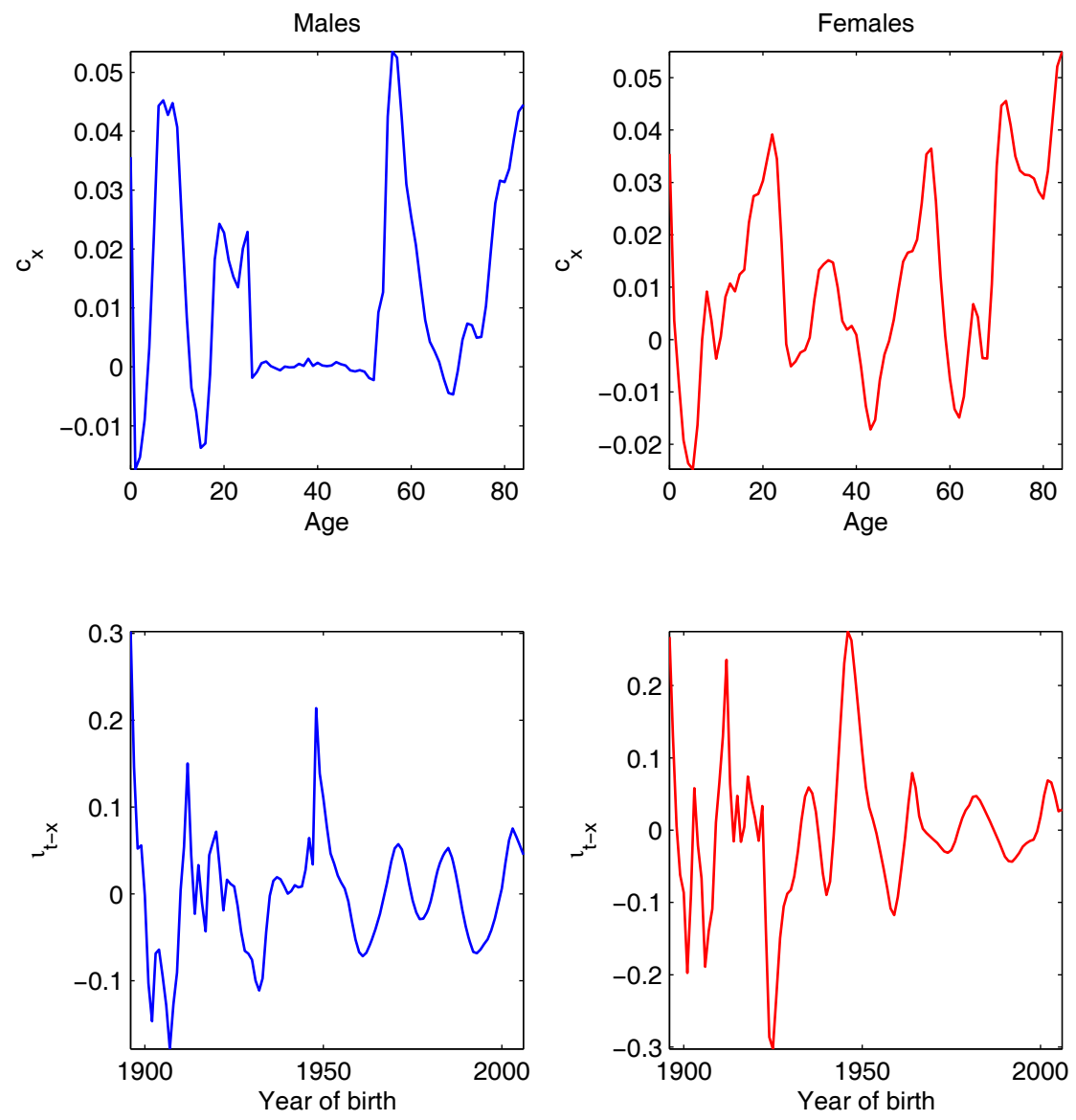

Figure 3. Maximum Likelihood Estimates of $c_{x}$ and $\iota_{t-x}$ in Renshaw and Haberman's (2006) Model

Table 2. Values of AIC and SBC for the Original Lee-Carter Model and Its Cohort-Based Extension

\begin{tabular}{ccc}
\hline Model & AIC & SBC \\
\hline & Males \\
Original & -10564 & -11129 \\
Cohort-based & -10612 & -11499 \\
& & \\
& Females & \\
Original & -9681 & -10246 \\
Cohort-based & -9738 & -10624 \\
\hline
\end{tabular}


To obtain a projection of future death rates, we model and extrapolate $\left\{k_{t}\right\}$ using an autoregressive integrated moving average (ARIMA) model ${ }^{10}$. On the basis of the Box and Jenkins' approach (Box and Jenkins, 1976), we find that the specification of $\operatorname{ARIMA}(2,1,0)$ fits well for both genders. In Figure 4 we show, separately for each gender, the sample autocorrelation function (ACF) for the residuals. The sample ACFs cut off at lag 0, indicating that the ARIMA models have adequately captured the serial correlations in $\left\{k_{t}\right\}$.

From the $\operatorname{ARIMA}(2,1,0)$ models we obtain a central projection of future mortality (see Figure 5). For readers' information, we also include in Figure 5 probabilistic confidence intervals that are generated by parametric bootstrapping (Brouhns et al., 2005). Other methods of attaching confidence intervals to the central projection include residual bootstrapping (Koissi et al., 2006), Markov Chain Monte Carlo (Czedo et al., 2005) and the generation of random deviations from the central estimates of model parameters (Renshaw and Haberman, 2008).

Given the mortality projection, we can readily compute the actuarial multipliers using the formulas shown in Table 1. Note that ${ }_{t} p_{x}$ in the formulas is a continuous function of time. We apply the procedure described in English Life Tables No. 15 (Office for National Statistics, 1997, p.17) to postulate ${ }_{t} p_{x}$ from discrete death probabilities. Examples of the multiplier tables (Multiplier Tables 7, 8, 27, and 28) are provided in the Appendix.

\footnotetext{
${ }^{10}$ We have examined whether the mortality indexes $k_{t}$ for men and women in Singapore are best described by stochastic trends (difference stationary models) or deterministic trends (trend stationary models). Such a distinction is important because mortality forecasts generated from these two classes of time-series models could be highly different. In particular, we applied the conventional Augmented Dickey-Fuller (ADF) test to examine the stationarity of the mortality indexes. The lag order of the model is selected based on the recursive $t$-statistic procedure suggested by $\mathrm{Ng}$ and Perron (1995). The finite sample critical values of the ADF test are simulated by a non-parametric bootstrap. The resulting test statistics are -1.60 and -1.80 for Singapore male and female $k_{t}$ indexes, respectively. We conclude that difference stationary models, such as the class of ARIMA processes, are more appropriate for modelling the $k_{t}$ data.
} 
The Singapore Economic Review

(c)World Scientific Publishing Company

(a) Males

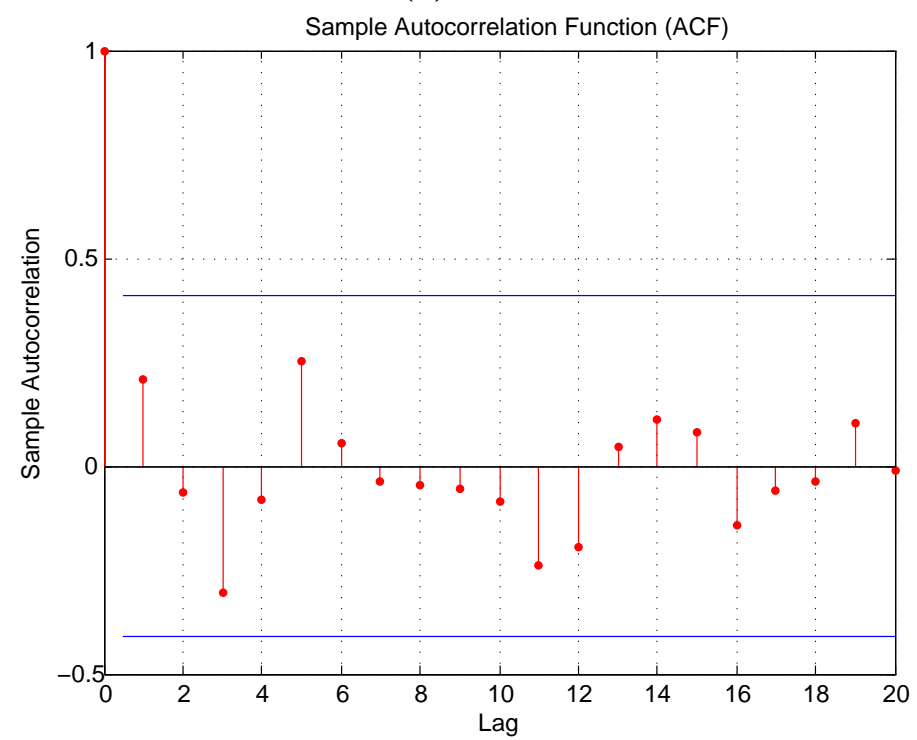

(b) Females

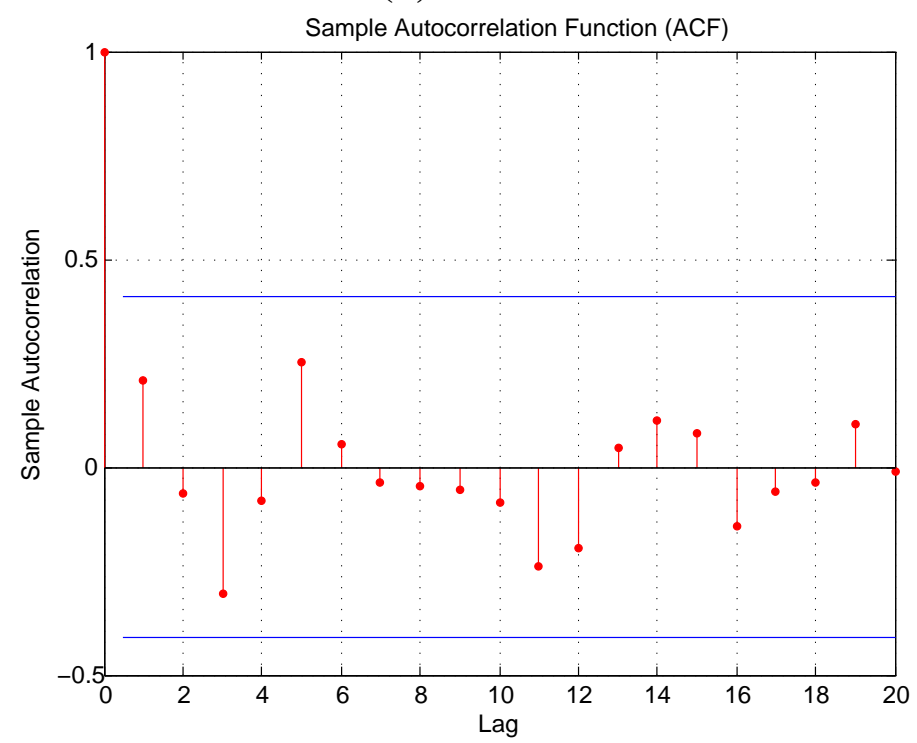

Figure 4. The Sample Autocorrelation Function for the Residuals from the ARIMA(2,1,0) Model 

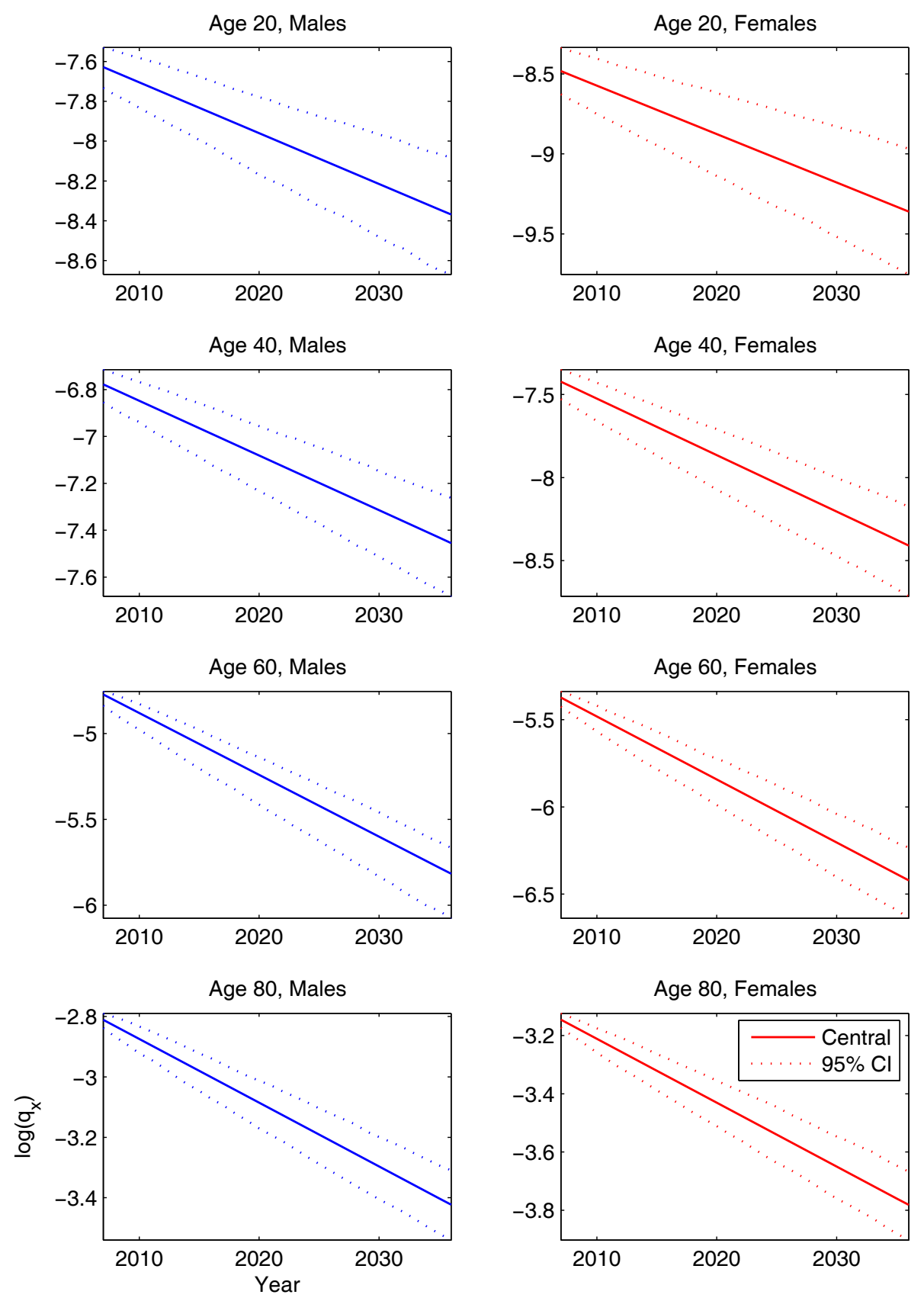

Figure 5. Projected Death Probabilities at Representative Ages

\section{The Discount Rate}

The discount rate, which may be considered the rate of return that a claimant can achieve on the lump sum of award before it is used up, is crucial in determining an appropriate multiplier. In England, judges used discount rates of about 4 to 5\% (net of tax) in personal injury cases before 1998, assuming that plaintiffs would invest in a spread of investments ranging from gilts 
to equity. However, the position was changed in deciding Wells v. Wells ([1999] 1 AC 345) in July 1998. In Wells v. Wells, the Lord Chancellor acknowledged that plaintiffs are different than ordinary investors in that they have a need for a dependable source of income to meet the costs of future care. Therefore, plaintiffs should not be required to take even moderate risk when they invest their damages awards.

"... I think the reality is that the plaintiffs in the present cases are not in the same position as other persons who have to rely on capital for future support. Unlike the great majority of persons who invest their capital, it is vital for the plaintiffs that they receive constant and costly nursing care for the remainder of their lives and that they should be able to pay for it, and any fall in income or depreciation in capital value of their investments will affect them much more severely than persons in better health who depend on their investment for support..." - Lord Hutton in Wells v Wells.

In England, the only investment that is free of even moderate risk is Index-Linked Government Stocks (ILGS) - the government guarantees the capital and income, and there is a protection from the erosion of purchasing power due to inflation. In deciding Wells v. Wells, the House of Lords ruled that the discount rate (net of tax) should be 3\% per annum, which was the prevailing rate of return on ILGS when the decision was made. The House of Lords also went on to lay down an authoritative guideline discount rate of $3 \%$ to be applied in other cases, until a rate was prescribed under Section 1 of the Damages Act 1996 by the Lord Chancellor.

On 25 June 2001, the Lord Chancellor made the Damages (Personal Injury) Order 2001 pursuant to Section 1 of the Damages Act 1996. On the basis of the arithmetic average of the gross redemption yields on ILGS (at an assumed rate of inflation of 3\%), for 3 years leading up to 8 June 2001, the Lord Chancellor decided a discount rate of $2.5 \%$, which would cover all personal injury cases in England in the foreseeable future. There are two advantages of using a fixed discount rate:

1. A fixed discount rate avoids deliberate delays in settlement resulting from one side's determination to gamble on the movement of the yield on ILGS.

2. A fixed discount rate eliminates the disparity of outcome between similar cases resolved or decided at different times.

Initially, the order was criticized by some personal injury practitioners (see, e.g., Hogg (2002)), but later the Lord Chancellor re-confirmed the authority of his decision with additional supporting reasons.

Following the current practice in England, the discount rate for personal injury cases in Singapore would be chosen by making reference to the yields on inflation-protected securities issued by the Government of Singapore. Such securities, however, are not available. To determine a real and risk-free rate of return that is applicable for personal injury settlements in Singapore, we consider the Fisher hypothesis (Fisher, 1930), which states that the nominal interest rate is the sum of the expected inflation rate and the ex ante real interest rate. That is,

$$
r=i-\pi^{e},
$$


where $r, i$ and $\pi^{e}$ are the ex ante real interest rate, the nominal interest rate and the expected inflation rate, respectively.

We obtain a proxy for $i$ by considering the (nominal) yields on Singapore Government Securities (SGS), which may be considered risk-free. Following the recommendations made by the Ogden Working Party and Lord Hope of Craighead in Wells v. Wells, we approximate $i$ by averaging the nominal yields on SGS with maturities over five years. Note that there is no single method by which the average yield may be calculated. Here we use a simple average, as how the Lord Chancellor decided the discount rate of $2.5 \%$ in the Damages (Personal Injury) Order 2001. Past yields on SGS are obtained from the Monetary Authority of Singapore (http://www.sgs.gov.sg).

The estimation of $\pi^{e}$ can be performed in different ways. One approach is to survey the public and ask what rate of inflation they expect (see, e.g., Thomas (1999)). However, if survey data are not available, economists usually use averages of past inflation rates to construct proxy measures for the expected rate (see, e.g., Fisher (2001, p.174)). In the absence of survey data, we use a three-year backward-looking moving average of annual inflation rates as a proxy measure for $\pi^{e}$. Past inflation rates (increase in CPI) in Singapore are obtained from Statistics Singapore (http://www.singstat.gov.sg).

In Figure 6 we show the estimates of $i$ and $\pi^{e}$ for the period of 1997-2007. On the basis of the Fisher hypothesis, the gap between the nominal yields (upper line) and the expected inflation rates (lower line) represent the real rates of return on risk-free securities in Singapore. We observe that the gap has been fairly stable, with an average of $2.57 \%$. Given the results of this empirical study, we recommend a discount rate of $2.5 \%$ (rounding $2.57 \%$ to the nearest half percent) per annum for use in personal injury settlements in Singapore. Note that no allowance for taxation is required since interests earned from SGS are exempted from tax.

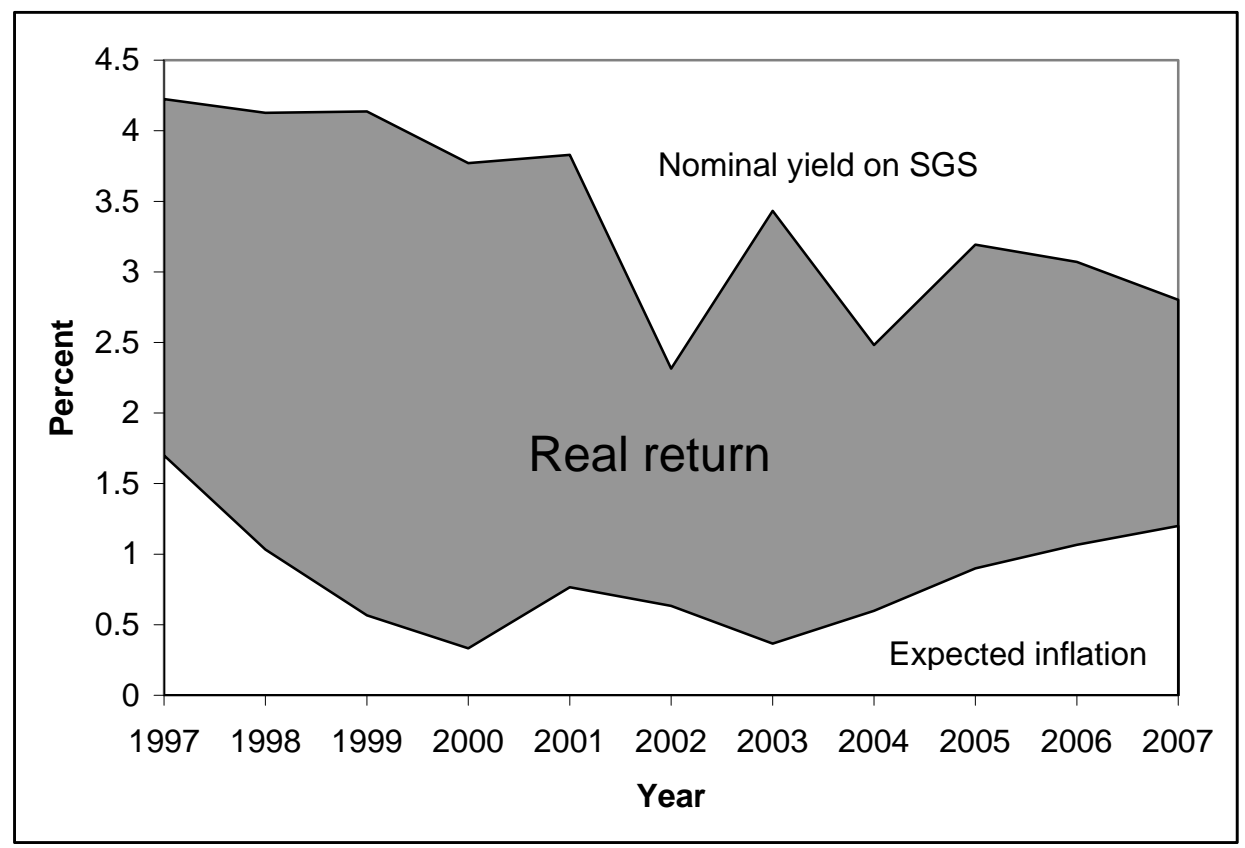

Figure 6. Estimated Real Rates of Return on Risk-Free Securities in Singapore 
The Singapore Economic Review

(c) World Scientific Publishing Company

Accepted 30 March 2010

Accepted Paper

\section{Two Examples}

In this section we illustrate the use of actuarial multipliers with two recent personal injury cases in Singapore. All multiplier tables involved in the illustrations are provided in the Appendix.

\subsection{Coh Eng Hong v. Management Corporation of Textile Centre and another ([2003] 1 SLR 209)}

The plaintiff was injured on May 1997 when the lift she was using fell 19 floors to the bottom of the lift shaft. At the time of the accident, she was 51 years old and was working as a host 'mamasan' at a nightclub in Singapore. She could not resume work after the accident because of injuries to her left lower limb, post-traumatic stress disorders and problems she had with her eyes.

In the interlocutory judgment, the assistant registrar (AR) used a multiplier (for loss of earnings) of 5 years, considering that the plaintiff was 54 years old at the time of the trial and that host 'mamasans' can work till 60 as long as they have their customers and 'daughters'. Based on a multiplier of 5 years and a multiplicand of SG\$32,400 per year, the plaintiff was awarded an amount of SG\$120,000 for post-trial loss of earnings.

Subsequently, the defendants appealed against the damages awarded. The judge in the High Court criticized the AR for overlooking the following matters:

1. 'Mamasans' are prone to come and go, as are the lounges and nightclubs they operate in. Therefore, there is a high chance of future redundancy (which may be considered a contingency other than mortality). Given this piece of uncertainty, the judge lowered the original multiplier by $40 \%$ to 3 years.

2. The plaintiff's eye problems were unrelated to the accident, although they were developed after the accident. Having considered this issue, the multiplicand was reduced to SG\$26,400 per annum.

Accordingly, the final amount awarded to the plaintiff for post-trial loss of earnings was SG\$79,200.

When we use the actuarial tables to make a decision on the multiplier, the post-trial loss of earnings would be computed as follows:

1. Look up Multiplier Table 8 for multipliers for loss of earnings to pension age 60 for females.

2. Given the information from Section 4, we choose a discount rate of $2.5 \%$.

3. Multiplier Table 8 shows that, on the basis of a $2.5 \%$ discount rate, the multiplier for a 54-year-old female is 5.53 years.

4. It is necessary to take account of contingencies other than mortality. Following the decision made by the judge in the High Court, we reduce the baseline multiplier by $40 \%$ to 


\subsection{2 years $^{11}$.}

5. Using the multiplicand decided by the judge in the High Court, the lump sum award for loss of future earnings is SG $\$ 87,648(3.32 \times 26,400)$.

\subsection{Tan Woei Jinn v. Thapjang Amorthap and another ([2005] 2 SLR 553)}

The plaintiff, a Malaysian, had been working in Singapore as a carpenter for SG\$1,500 per month at the time of the accident. After the accident in which he was seriously injured, the plaintiff returned to Malaysia and found employment repairing telephones for SG\$220 a month.

Having considered the plaintiff's age (20-year-old), the AR adopted a multiplier of 15 years when calculating the plaintiff's loss of future earnings. She applied the multiplier to two multiplicands:

1. SG $\$ 1,280$ per month $(\$ 1,500-\$ 220)$ for the first ten years;

2. SG $\$ 2,780$ per month $(\$ 3,000-\$ 220)$ for the next five years.

As a result, the plaintiff was awarded an amount of SG $\$ 320,400$ for the loss of future earnings in the interlocutory judgment.

The defendants then appealed against the amount awarded. In the High Court, the judge pointed out the following two errors made in the interlocutory judgment:

1. The AR was wrong on the plaintiff's age. The plaintiff was 22 , but not 20 , years old when the awards were made.

2. The AR did not consider the possibility that the plaintiff would return home before the end of his working life, and that the plaintiff would earn a different wage on returning home.

The judge believed that the error in the plaintiff's age was immaterial and therefore did not change the multiplier. However, the judge thought that it would be more reasonable to assume that the plaintiff would return to Malaysia after 10 years even if the accident had not occurred. Provided that the plaintiff would work until age 60, he would work for 28 years on returning to Malaysia.

Given the above considerations, the judge split the multiplier of 15 years into two portions: the first portion (4 years) was applied to the anticipated loss of earnings (SG\$1,280 per month) in Singapore, while the remaining portion (11 years) was applied to the anticipated loss of

\footnotetext{
${ }^{11}$ The court should consider the impact of contingencies (such as sickness, unemployment and stoppages) other than mortality on working life. Tables of reduction factors to be applied to the multipliers were first introduced in the Second Edition of the Ogden Tables, and they were significantly expanded in the Sixth Edition of the Tables (Section B). These factors were based on studies by a number of researchers in the United Kingdom. It would not be practical for the Singapore courts to simply adopt the exact Tables of reduction factors in the Ogden Tables, as they were constructed in the light of labour force circumstances in the United Kingdom, not of Singapore. However, these factors can serve as a benchmark for Singapore judges.
} 
earnings (SG\$530 per month) in Malaysia. As a result, the amount awarded to the plaintiff was SG\$131,400 $(4 \times 1,280 \times 12+11 \times 530 \times 12)$.

Alternatively, we can use the actuarial tables to compute the lump sum award for loss of future earnings. Assuming a discount rate of $2.5 \%$ as in the previous case, we have the following procedure to compute the post-trial loss of earnings:

The loss of future earnings in Singapore:

1. Look up Multiplier Table 28 for multipliers for pecuniary loss for term certain.

2. Multiplier Table 28 shows that, on the basis of a $2.5 \%$ discount rate, the multiplier for a certain term of 10 years is 8.86 years.

3. Given a multiplicand of SG $\$ 1,280 \times 12$ per year, the estimated loss of future earnings in Singapore is $\mathrm{SG} \$ 136,090(8.86 \times 1,280 \times 12)$.

The loss of future earnings in Malaysia ${ }^{12}$ :

1. Look up Multiplier Table 7 for multipliers for loss of earnings to pension age 60 for males.

2. The judge assumed that the plaintiff would return to Malaysia at age 32 (10 years from now). Multiplier Table 7 shows that, on the basis of $2.5 \%$ discount rate, the multiplier for a 32-year-old male is 19.99 years.

3. The multiplier must be discounted to the time when the award was made. Multiplier Table 27 shows that, on the basis of $2.5 \%$ discount rate, the discounting factor for a certain term of 10 years is 0.7812 . The correct multiplier is therefore 15.62 years $(0.7812 \times 19.99)$.

4. Given a multiplicand of SG $\$ 530 \times 12$ per year, the estimated loss of future earnings in Malaysia is SG $\$ 99,343(15.62 \times 530 \times 12)$.

Using an actuarial approach, the lump sum award for future earnings is SG\$235,433 (136,090 $+99,343)$. Note that we made no allowance for the plaintiff's mortality from age 22 to 32 . However, since mortality rates for this age range are very low, this assumption has only a minimal effect on the resulting multipliers ${ }^{13}$.

\section{Conclusion and Future Research}

In personal injury and fatal accident cases, assessing the entitlement of a claimant is a complicated process. The actuarial multiplier tables, which involve input from lawyers, actuaries and

\footnotetext{
${ }^{12}$ The traditional English approach had treated matters of quantification of damages in personal injury litigation as matters of procedure rather than substance. The paragraph 7-004 of Collins et al. (2008) states: The primary objective of this Rule is to obviate the inconvenience of conducting the trial of a case containing foreign elements in a manner with which the court is unfamiliar. The plaintiff is a Malaysian but the trial was conducted in Singapore. We assume that the court follows the traditional English approach and applies the Singapore Multiplier Tables no matter the person is living in Malaysia or Singapore.

${ }^{13}$ If the age range under consideration is high, then the court should ask an actuarial expert to compute an actuarial discount factor.
} 
other experts, can ensure that the principle of restitutio in integrum is properly applied. The lump sum award computed from an appropriate actuarial multiplier is fair from the following viewpoints:

1. The award, if invested in risk-free securities, would generate a stream of income that is, on an inflation-adjusted basis, equal to the annual loss of earnings and/or other benefits assessed in the law court.

2. Although the claimant may die immediately after the trial or survive to extreme ages, the actuarially calculated award would, on average, exhaust on the claimant's date of death, considering a large number of claimants.

The conventional approach to choosing multipliers tends to result in under-compensation. In both cases we discussed in Section 5, the amount awarded to the plaintiff is significantly lower than that we computed from the actuarial multipliers (see Table 3). Luckett and Craner (1994) also found in an empirical study that multipliers that are determined by the conventional board-brush approach are consistently lower than the corresponding actuarial multipliers. Although courts in Singapore are still relying on the conventional approach, the need for reform is obvious. The multipliers tables we construct in this study will provide an important tool for courts in Singapore to use to ensure that an accurate and fair level of compensation is calculated for each case.

Table 3. Awards Based on the Conventional Approach (the Actual Amount Awarded) and the Actuarial Approach

\begin{tabular}{lcc}
\hline & Conventional approach & Actuarial approach \\
\hline The case in Section 5.1 & SG $\$ 79,200$ & SG $\$ 87,648$ \\
The case in Section 5.2 & SG $\$ 131,400$ & SG $\$ 235,433$ \\
\hline
\end{tabular}

Readers are reminded that the baseline multipliers take no account of risks other than mortality. The Explanatory Notes of the Ogden Tables provide tables of reduction factors, which serve as a 'ready reckenor' for adjusting the baseline multipliers according to the employment status, disability status and education attainment of the claimant. These reduction factors were initially based on the work of Haberman and Bloomfield (1990). They were then revised in the Fifth Edition of the Ogden Tables on the basis of the study carried out by Butt et al. (2008) in which reduction factors are modeled by a multiple-state Markov process that is fitted to the data from UK Labour Force Surveys for 1973, 1977, 1981 and 1985. Tables of reduction factors for use in Singapore can be produced in future research when sufficient information on the morbidity and labor force participation of Singaporeans is available.

Mortality data reported by the Singapore Department of Statistics (SDS) are given by age intervals and various assumptions are needed to extract individual age mortality rates. This introduces a source of error in those rates, although this is unlikely to be serious. In any case, it is necessary to verify that the approach of estimating individual age mortality rates produces reasonable results. Furthermore, the mortality rates produced by SDS relate to the general population. A plaintiff may be subject to lighter or heavier mortality than the general population 
depending on his/her health conditions, occupational hazards, etc. Adjustment factors need to be produced to account of these deviations from the 'average' population mortality. To produce multipliers that address these two points requires a great deal of data. At this stage, with the paucity of data, it is probably not feasible to embark on such a large scale exercise. Nevertheless, it may be a worthwhile project to undertake in the future.

We conclude from the patterns of inflation rates and nominal yields on SGS for the past 10 years that a discount rate of $2.5 \%$ is appropriate for use in personal injury cases in Singapore. This figure is less precise than could be achieved, but it is important to keep calculations simple and accurate in legal applications. Further, the use of a fixed discount rate eliminates potential arguments about the applicable rate, and avoids the complexity and extra costs that a mathematical formula would entail. However, when the anticipated award is large, a small difference in the discount rate can be material and therefore a more exact calculation may be necessary. In this case, a consideration of stochastic investment models, for example, the Wilkie Model (Wilkie, 1995), is warranted.

The most serious criticism of lump sum awards for personal injury is that there is a need to forecast the real rate of return and how long the payments will be required. The need for forecasting may be avoided by making lifetime periodic payments to the claimant. Recently, judges in Britain have been given the power to make a periodical payment order (PPO), even if it is against the wishes of both parties. ${ }^{14}$ Rather than having a clean break, a PPO will produce an uncertain continuing relationship that may vary over time, because the payments must be indexed against inflation and they can be set to continue for the claimant's lifetime. In addition, judges can arrange for the awards to be varied, if necessary, long after trial.

However, the court's power to make a PPO is limited in the following three aspects: (1) the power cannot be exercised in respect of damages for past pecuniary loss unless the parties agree; (2) a PPO can only be made if the continuity of payment is 'reasonably secure, by which it means the payments are to be made by a government of health service body, or they are protected by a compensation scheme which guarantees payment in the event of an insurer's insolvency; (3) the power to impose periodic payments can only be exercised if the case comes to the court for the judge to make the order. ${ }^{15}$ As the scope to make a PPO is rather limited, in Britain, the practice of making lump sum payments is still pervasive, and the importance of the actuarial multiplier tables remains.

As described in Lewis (1993, 2006) and Langstaff (2003), from the claimants' viewpoint, this newer form of payment is attractive for several reasons. First, it offers claimants greater certainty and security. Second, it is not reliant on uncertain forecasts of inflation and life expectancy. Third, it can relieve a claimant from the stress of having to invest and avoid the costs of obtaining financial advice. However, when periodic payments are made, the defendant has to absorb all risks (investment and mortality) involved. Insurers in Britain are not in favor of the new legislation, due partly to the challenge of setting reserves when future liability is highly uncertain, and partly to the difficulty in deciding the threshold above which the liability is reinsured. In fact, according to Lewis (2006), only a bare majority (57\%) of respondents to the Lord Chancellor's consultation paper gave an unqualified welcome to the imposition of PPOs.

\footnotetext{
${ }^{14}$ Such power follows from the amendment of the Damages Act 1996 . The changes were made by s100 and s101 of the Courts Act 2003, but these sections did not come into force until April 2005.

${ }^{15}$ Lewis (2006) provides a further discussion on the scope to make a PPO.
} 
The Singapore Economic Review

(c) World Scientific Publishing Company

Accepted 30 March 2010

Accepted Paper

Since the issue of the power to make a PPO is such controversial, we anticipate a lengthy consultation before there is any change to the personal injury legislation in Singapore. Significant further research, for example, on the impact of PPOs on the insurance industry in Singapore, is demanded. For the time being, the lump sum approach is dominant in Singapore, and the multiplier tables we provide in this article would serve as a useful tool for personal injury practitioners in Singapore.

\section{Acknowledgments}

The first two authors wish to acknowledge and express their appreciation for the support of a research grant from the Research Grants Council of the Hong Kong Special Administrative Region (General Research Fund Project No. HKU 741408H). Johnny S.H. Li's work was partially supported by a grant from the Natural Science and Engineering Research Council of Canada. 
The Singapore Economic Review (c)World Scientific Publishing Company

\section{Appendix: Multiplier tables involved in Section 5}

Multiplier Table 7

Multipliers for Loss of Earnings to Pension Age 60 (Males)

\begin{tabular}{|c|c|c|c|c|c|c|c|c|c|c|c|}
\hline \multirow[b]{2}{*}{ Age at date of trial } & \multicolumn{11}{|c|}{ Multiplier calculated at a rate of return of } \\
\hline & $0.0 \%$ & $0.5 \%$ & $1.0 \%$ & $1.5 \%$ & $2.0 \%$ & $2.5 \%$ & $3.0 \%$ & $3.5 \%$ & $4.0 \%$ & $4.5 \%$ & $5.0 \%$ \\
\hline 16 & 43.57 & 39.14 & 35.32 & 32.01 & 29.13 & 26.63 & 24.44 & 22.51 & 20.82 & 19.32 & 17.99 \\
\hline 17 & 42.57 & 38.33 & 34.66 & 31.48 & 28.71 & 26.28 & 24.15 & 22.28 & 20.63 & 19.17 & 17.87 \\
\hline 18 & 41.57 & 37.52 & 34.00 & 30.94 & 28.27 & 25.93 & 23.87 & 22.05 & 20.44 & 19.01 & 17.74 \\
\hline 19 & 40.57 & 36.71 & 33.34 & 30.40 & 27.83 & 25.56 & 23.57 & 21.80 & 20.24 & 18.85 & 17.60 \\
\hline 20 & 39.57 & 35.89 & 32.67 & 29.85 & 27.38 & 25.19 & 23.26 & 21.55 & 20.03 & 18.67 & 17.46 \\
\hline 21 & 38.58 & 35.07 & 32.00 & 29.30 & 26.92 & 24.82 & 22.95 & 21.30 & 19.82 & 18.50 & 17.31 \\
\hline 22 & 37.59 & 34.26 & 31.32 & 28.74 & 26.46 & 24.43 & 22.63 & 21.03 & 19.60 & 18.31 & 17.16 \\
\hline 23 & 36.60 & 33.43 & 30.64 & 28.17 & 25.99 & 24.04 & 22.31 & 20.76 & 19.37 & 18.12 & 17.00 \\
\hline 24 & 35.61 & 32.61 & 29.95 & 27.60 & 25.50 & 23.64 & 21.97 & 20.47 & 19.13 & 17.92 & 16.83 \\
\hline 25 & 34.62 & 31.78 & 29.25 & 27.01 & 25.01 & 23.22 & 21.62 & 20.18 & 18.88 & 17.71 & 16.66 \\
\hline 26 & 33.62 & 30.94 & 28.55 & 26.41 & 24.51 & 22.79 & 21.26 & 19.87 & 18.62 & 17.49 & 16.47 \\
\hline 27 & 32.62 & 30.09 & 27.83 & 25.81 & 23.99 & 22.36 & 20.88 & 19.55 & 18.35 & 17.26 & 16.27 \\
\hline 28 & 31.63 & 29.24 & 27.11 & 25.19 & 23.46 & 21.90 & 20.50 & 19.22 & 18.07 & 17.02 & 16.06 \\
\hline 29 & 30.63 & 28.39 & 26.37 & 24.56 & 22.92 & 21.44 & 20.10 & 18.88 & 17.77 & 16.77 & 15.84 \\
\hline 30 & 29.63 & 27.53 & 25.64 & 23.92 & 22.37 & 20.97 & 19.69 & 18.53 & 17.47 & 16.50 & 15.61 \\
\hline 31 & 28.63 & 26.67 & 24.89 & 23.28 & 21.81 & 20.48 & 19.27 & 18.16 & 17.15 & 16.22 & 15.37 \\
\hline 32 & 27.64 & 25.80 & 24.14 & 22.62 & 21.25 & 19.99 & 18.84 & 17.79 & 16.82 & 15.94 & 15.12 \\
\hline 33 & 26.64 & 24.93 & 23.38 & 21.96 & 20.66 & 19.48 & 18.39 & 17.39 & 16.48 & 15.63 & 14.86 \\
\hline 34 & 25.65 & 24.06 & 22.61 & 21.29 & 20.07 & 18.96 & 17.93 & 16.99 & 16.12 & 15.32 & 14.58 \\
\hline 35 & 24.65 & 23.18 & 21.84 & 20.60 & 19.47 & 18.43 & 17.46 & 16.57 & 15.75 & 14.99 & 14.29 \\
\hline 36 & 23.66 & 22.30 & 21.06 & 19.91 & 18.86 & 17.88 & 16.98 & 16.14 & 15.37 & 14.65 & 13.98 \\
\hline 37 & 22.66 & 21.42 & 20.27 & 19.21 & 18.23 & 17.32 & 16.48 & 15.70 & 14.97 & 14.29 & 13.66 \\
\hline 38 & 21.67 & 20.53 & 19.48 & 18.50 & 17.59 & 16.75 & 15.96 & 15.23 & 14.55 & 13.92 & 13.33 \\
\hline 39 & 20.68 & 19.64 & 18.67 & 17.78 & 16.94 & 16.16 & 15.44 & 14.76 & 14.12 & 13.53 & 12.98 \\
\hline 40 & 19.69 & 18.75 & 17.87 & 17.04 & 16.28 & 15.56 & 14.89 & 14.27 & 13.68 & 13.13 & 12.61 \\
\hline 41 & 18.70 & 17.85 & 17.05 & 16.30 & 15.60 & 14.95 & 14.33 & 13.76 & 13.21 & 12.71 & 12.23 \\
\hline 42 & 17.71 & 16.95 & 16.23 & 15.55 & 14.92 & 14.32 & 13.76 & 13.23 & 12.73 & 12.26 & 11.82 \\
\hline 43 & 16.73 & 16.04 & 15.40 & 14.79 & 14.22 & 13.68 & 13.17 & 12.69 & 12.23 & 11.81 & 11.40 \\
\hline 44 & 15.74 & 15.13 & 14.56 & 14.02 & 13.51 & 13.02 & 12.56 & 12.13 & 11.72 & 11.33 & 10.95 \\
\hline 45 & 14.76 & 14.22 & 13.72 & 13.23 & 12.78 & 12.35 & 11.94 & 11.55 & 11.18 & 10.82 & 10.49 \\
\hline 46 & 13.77 & 13.30 & 12.86 & 12.44 & 12.04 & 11.66 & 11.29 & 10.95 & 10.62 & 10.30 & 10.00 \\
\hline 47 & 12.79 & 12.38 & 12.00 & 11.63 & 11.28 & 10.95 & 10.63 & 10.32 & 10.03 & 9.75 & 9.49 \\
\hline 48 & 11.80 & 11.46 & 11.13 & 10.81 & 10.51 & 10.22 & 9.95 & 9.68 & 9.43 & 9.18 & 8.95 \\
\hline 49 & 10.82 & 10.53 & 10.25 & 9.98 & 9.73 & 9.48 & 9.25 & 9.02 & 8.80 & 8.59 & 8.39 \\
\hline 50 & 9.84 & 9.60 & 9.37 & 9.14 & 8.93 & 8.72 & 8.52 & 8.33 & 8.15 & 7.97 & 7.80 \\
\hline 51 & 8.85 & 8.66 & 8.47 & 8.29 & 8.12 & 7.95 & 7.78 & 7.62 & 7.47 & 7.32 & 7.18 \\
\hline 52 & 7.87 & 7.72 & 7.57 & 7.43 & 7.29 & 7.15 & 7.02 & 6.89 & 6.76 & 6.64 & 6.53 \\
\hline 53 & 6.89 & 6.78 & 6.66 & 6.55 & 6.44 & 6.33 & 6.23 & 6.13 & 6.03 & 5.94 & 5.85 \\
\hline 54 & 5.91 & 5.83 & 5.74 & 5.66 & 5.58 & 5.50 & 5.42 & 5.35 & 5.27 & 5.20 & 5.13 \\
\hline 55 & 4.93 & 4.87 & 4.81 & 4.76 & 4.70 & 4.64 & 4.59 & 4.54 & 4.48 & 4.43 & 4.38 \\
\hline 56 & 3.95 & 3.92 & 3.88 & 3.84 & 3.80 & 3.77 & 3.73 & 3.70 & 3.66 & 3.63 & 3.59 \\
\hline 57 & 2.97 & 2.95 & 2.93 & 2.91 & 2.89 & 2.86 & 2.84 & 2.82 & 2.80 & 2.78 & 2.77 \\
\hline 58 & 1.99 & 1.98 & 1.97 & 1.96 & 1.95 & 1.94 & 1.93 & 1.92 & 1.91 & 1.90 & 1.89 \\
\hline 59 & 1.00 & 0.99 & 0.99 & 0.99 & 0.99 & 0.98 & 0.98 & 0.98 & 0.98 & 0.97 & 0.97 \\
\hline
\end{tabular}


The Singapore Economic Review (c)World Scientific Publishing Company

Multiplier Table 8

Multipliers for Loss of Earnings to Pension Age 60 (Females)

\begin{tabular}{|c|c|c|c|c|c|c|c|c|c|c|c|}
\hline \multirow[b]{2}{*}{ Age at date of trial } & \multicolumn{11}{|c|}{ Multiplier calculated at a rate of return of } \\
\hline & $0.0 \%$ & $0.5 \%$ & $1.0 \%$ & $1.5 \%$ & $2.0 \%$ & $2.5 \%$ & $3.0 \%$ & $3.5 \%$ & $4.0 \%$ & $4.5 \%$ & $5.0 \%$ \\
\hline 16 & 43.80 & 39.33 & 35.48 & 32.15 & 29.26 & 26.74 & 24.53 & 22.60 & 20.89 & 19.39 & 18.05 \\
\hline 17 & 42.80 & 38.53 & 34.83 & 31.63 & 28.83 & 26.39 & 24.25 & 22.37 & 20.71 & 19.24 & 17.93 \\
\hline 18 & 41.80 & 37.72 & 34.18 & 31.10 & 28.40 & 26.04 & 23.97 & 22.14 & 20.52 & 19.08 & 17.80 \\
\hline 19 & 40.80 & 36.91 & 33.52 & 30.56 & 27.96 & 25.68 & 23.67 & 21.90 & 20.32 & 18.92 & 17.67 \\
\hline 20 & 39.80 & 36.09 & 32.85 & 30.01 & 27.51 & 25.31 & 23.37 & 21.65 & 20.12 & 18.75 & 17.53 \\
\hline 21 & 38.80 & 35.27 & 32.17 & 29.45 & 27.05 & 24.94 & 23.06 & 21.39 & 19.90 & 18.57 & 17.38 \\
\hline 22 & 37.80 & 34.44 & 31.49 & 28.89 & 26.59 & 24.55 & 22.74 & 21.12 & 19.68 & 18.39 & 17.23 \\
\hline 23 & 36.80 & 33.61 & 30.80 & 28.31 & 26.11 & 24.15 & 22.41 & 20.85 & 19.45 & 18.20 & 17.07 \\
\hline 24 & 35.80 & 32.78 & 30.10 & 27.73 & 25.62 & 23.74 & 22.06 & 20.56 & 19.21 & 17.99 & 16.90 \\
\hline 25 & 34.80 & 31.94 & 29.40 & 27.14 & 25.13 & 23.33 & 21.71 & 20.26 & 18.96 & 17.78 & 16.72 \\
\hline 26 & 33.80 & 31.10 & 28.69 & 26.54 & 24.62 & 22.90 & 21.35 & 19.96 & 18.70 & 17.56 & 16.53 \\
\hline 27 & 32.80 & 30.25 & 27.97 & 25.93 & 24.10 & 22.46 & 20.97 & 19.64 & 18.43 & 17.33 & 16.33 \\
\hline 28 & 31.80 & 29.40 & 27.25 & 25.31 & 23.57 & 22.01 & 20.59 & 19.31 & 18.14 & 17.09 & 16.13 \\
\hline 29 & 30.80 & 28.54 & 26.51 & 24.69 & 23.04 & 21.54 & 20.19 & 18.97 & 17.85 & 16.83 & 15.91 \\
\hline 30 & 29.80 & 27.68 & 25.77 & 24.05 & 22.49 & 21.07 & 19.78 & 18.61 & 17.55 & 16.57 & 15.68 \\
\hline 31 & 28.80 & 26.82 & 25.03 & 23.40 & 21.93 & 20.59 & 19.36 & 18.25 & 17.23 & 16.30 & 15.44 \\
\hline 32 & 27.80 & 25.95 & 24.27 & 22.75 & 21.36 & 20.09 & 18.93 & 17.87 & 16.90 & 16.01 & 15.19 \\
\hline 33 & 26.80 & 25.08 & 23.51 & 22.08 & 20.78 & 19.58 & 18.49 & 17.48 & 16.56 & 15.71 & 14.92 \\
\hline 34 & 25.80 & 24.20 & 22.74 & 21.41 & 20.18 & 19.06 & 18.03 & 17.08 & 16.20 & 15.39 & 14.65 \\
\hline 35 & 24.80 & 23.33 & 21.97 & 20.72 & 19.58 & 18.53 & 17.56 & 16.66 & 15.83 & 15.07 & 14.36 \\
\hline 36 & 23.81 & 22.44 & 21.19 & 20.03 & 18.96 & 17.98 & 17.07 & 16.23 & 15.45 & 14.73 & 14.05 \\
\hline 37 & 22.81 & 21.55 & 20.40 & 19.33 & 18.34 & 17.42 & 16.57 & 15.78 & 15.05 & 14.37 & 13.73 \\
\hline 38 & 21.81 & 20.66 & 19.60 & 18.61 & 17.70 & 16.85 & 16.06 & 15.32 & 14.63 & 14.00 & 13.40 \\
\hline 39 & 20.82 & 19.77 & 18.79 & 17.89 & 17.04 & 16.26 & 15.53 & 14.84 & 14.20 & 13.61 & 13.05 \\
\hline 40 & 19.82 & 18.87 & 17.98 & 17.15 & 16.38 & 15.66 & 14.98 & 14.35 & 13.76 & 13.20 & 12.68 \\
\hline 41 & 18.83 & 17.96 & 17.16 & 16.41 & 15.70 & 15.04 & 14.42 & 13.84 & 13.29 & 12.78 & 12.29 \\
\hline 42 & 17.83 & 17.06 & 16.33 & 15.65 & 15.01 & 14.41 & 13.84 & 13.31 & 12.81 & 12.33 & 11.89 \\
\hline 43 & 16.84 & 16.15 & 15.50 & 14.88 & 14.31 & 13.76 & 13.25 & 12.76 & 12.30 & 11.87 & 11.46 \\
\hline 44 & 15.85 & 15.23 & 14.65 & 14.11 & 13.59 & 13.10 & 12.64 & 12.20 & 11.78 & 11.39 & 11.02 \\
\hline 45 & 14.85 & 14.31 & 13.80 & 13.32 & 12.86 & 12.42 & 12.01 & 11.61 & 11.24 & 10.89 & 10.55 \\
\hline 46 & 13.86 & 13.39 & 12.94 & 12.52 & 12.11 & 11.73 & 11.36 & 11.01 & 10.68 & 10.36 & 10.06 \\
\hline 47 & 12.87 & 12.46 & 12.08 & 11.71 & 11.35 & 11.02 & 10.69 & 10.39 & 10.09 & 9.81 & 9.54 \\
\hline 48 & 11.88 & 11.53 & 11.20 & 10.88 & 10.58 & 10.29 & 10.01 & 9.74 & 9.48 & 9.24 & 9.00 \\
\hline 49 & 10.89 & 10.60 & 10.32 & 10.05 & 9.79 & 9.54 & 9.30 & 9.07 & 8.85 & 8.64 & 8.44 \\
\hline 50 & 9.90 & 9.66 & 9.43 & 9.20 & 8.99 & 8.78 & 8.58 & 8.38 & 8.20 & 8.02 & 7.84 \\
\hline 51 & 8.91 & 8.72 & 8.53 & 8.34 & 8.17 & 8.00 & 7.83 & 7.67 & 7.52 & 7.37 & 7.22 \\
\hline 52 & 7.93 & 7.77 & 7.62 & 7.47 & 7.33 & 7.20 & 7.06 & 6.93 & 6.81 & 6.69 & 6.57 \\
\hline 53 & 6.94 & 6.82 & 6.70 & 6.59 & 6.48 & 6.37 & 6.27 & 6.17 & 6.07 & 5.97 & 5.88 \\
\hline 54 & 5.95 & 5.86 & 5.78 & 5.69 & 5.61 & 5.53 & 5.46 & 5.38 & 5.31 & 5.23 & 5.16 \\
\hline 55 & 4.96 & 4.90 & 4.84 & 4.78 & 4.73 & 4.67 & 4.62 & 4.56 & 4.51 & 4.46 & 4.41 \\
\hline 56 & 3.97 & 3.94 & 3.90 & 3.86 & 3.82 & 3.79 & 3.75 & 3.71 & 3.68 & 3.65 & 3.61 \\
\hline 57 & 2.98 & 2.96 & 2.94 & 2.92 & 2.90 & 2.88 & 2.86 & 2.84 & 2.82 & 2.80 & 2.78 \\
\hline 58 & 1.99 & 1.98 & 1.97 & 1.96 & 1.95 & 1.94 & 1.93 & 1.93 & 1.92 & 1.91 & 1.90 \\
\hline 59 & 1.00 & 1.00 & 0.99 & 0.99 & 0.99 & 0.99 & 0.98 & 0.98 & 0.98 & 0.98 & 0.97 \\
\hline
\end{tabular}


The Singapore Economic Review (c)World Scientific Publishing Company

Multiplier Table 27

Discounting Factors for Term Certain

\begin{tabular}{|c|c|c|c|c|c|c|c|c|c|c|}
\hline \multirow[b]{2}{*}{ Term } & \multicolumn{10}{|c|}{ Factor to discount value of multiplier for a period of deferment } \\
\hline & $0.5 \%$ & $1.0 \%$ & $1.5 \%$ & $2.0 \%$ & $2.5 \%$ & $3.0 \%$ & $3.5 \%$ & $4.0 \%$ & $4.5 \%$ & $5.0 \%$ \\
\hline 1 & 0.9950 & 0.9901 & 0.9852 & 0.9804 & 0.9756 & 0.9709 & 0.9662 & 0.9615 & 0.9569 & 0.9524 \\
\hline 2 & 0.9901 & 0.9803 & 0.9707 & 0.9612 & 0.9518 & 0.9426 & 0.9335 & 0.9246 & 0.9157 & 0.9070 \\
\hline 3 & 0.9851 & 0.9706 & 0.9563 & 0.9423 & 0.9286 & 0.9151 & 0.9019 & 0.8890 & 0.8763 & 0.8638 \\
\hline 4 & 0.9802 & 0.9610 & 0.9422 & 0.9238 & 0.9060 & 0.8885 & 0.8714 & 0.8548 & 0.8386 & 0.8227 \\
\hline 5 & 0.9754 & 0.9515 & 0.9283 & 0.9057 & 0.8839 & 0.8626 & 0.8420 & 0.8219 & 0.8025 & 0.7835 \\
\hline 6 & 0.9705 & 0.9420 & 0.9145 & 0.8880 & 0.8623 & 0.8375 & 0.8135 & 0.7903 & 0.7679 & 0.7462 \\
\hline 7 & 0.9657 & 0.9327 & 0.9010 & 0.8706 & 0.8413 & 0.8131 & 0.7860 & 0.7599 & 0.7348 & 0.7107 \\
\hline 8 & 0.9609 & 0.9235 & 0.8877 & 0.8535 & 0.8207 & 0.7894 & 0.7594 & 0.7307 & 0.7032 & 0.6768 \\
\hline 9 & 0.9561 & 0.9143 & 0.8746 & 0.8368 & 0.8007 & 0.7664 & 0.7337 & 0.7026 & 0.6729 & 0.6446 \\
\hline 10 & 0.9513 & 0.9053 & 0.8617 & 0.8203 & 0.7812 & 0.7441 & 0.7089 & 0.6756 & 0.6439 & 0.6139 \\
\hline 11 & 0.9466 & 0.8963 & 0.8489 & 0.8043 & 0.7621 & 0.7224 & 0.6849 & 0.6496 & 0.6162 & 0.5847 \\
\hline 12 & 0.9419 & 0.8874 & 0.8364 & 0.7885 & 0.7436 & 0.7014 & 0.6618 & 0.6246 & 0.5897 & 0.5568 \\
\hline 13 & 0.9372 & 0.8787 & 0.8240 & 0.7730 & 0.7254 & 0.6810 & 0.6394 & 0.6006 & 0.5643 & 0.5303 \\
\hline 14 & 0.9326 & 0.8700 & 0.8118 & 0.7579 & 0.7077 & 0.6611 & 0.6178 & 0.5775 & 0.5400 & 0.5051 \\
\hline 15 & 0.9279 & 0.8613 & 0.7999 & 0.7430 & 0.6905 & 0.6419 & 0.5969 & 0.5553 & 0.5167 & 0.4810 \\
\hline 16 & 0.9233 & 0.8528 & 0.7880 & 0.7284 & 0.6736 & 0.6232 & 0.5767 & 0.5339 & 0.4945 & 0.4581 \\
\hline 17 & 0.9187 & 0.8444 & 0.7764 & 0.7142 & 0.6572 & 0.6050 & 0.5572 & 0.5134 & 0.4732 & 0.4363 \\
\hline 18 & 0.9141 & 0.8360 & 0.7649 & 0.7002 & 0.6412 & 0.5874 & 0.5384 & 0.4936 & 0.4528 & 0.4155 \\
\hline 19 & 0.9096 & 0.8277 & 0.7536 & 0.6864 & 0.6255 & 0.5703 & 0.5202 & 0.4746 & 0.4333 & 0.3957 \\
\hline 20 & 0.9051 & 0.8195 & 0.7425 & 0.6730 & 0.6103 & 0.5537 & 0.5026 & 0.4564 & 0.4146 & 0.3769 \\
\hline 21 & 0.9006 & 0.8114 & 0.7315 & 0.6598 & 0.5954 & 0.5375 & 0.4856 & 0.4388 & 0.3968 & 0.3589 \\
\hline 22 & 0.8961 & 0.8034 & 0.7207 & 0.6468 & 0.5809 & 0.5219 & 0.4692 & 0.4220 & 0.3797 & 0.3418 \\
\hline 23 & 0.8916 & 0.7954 & 0.7100 & 0.6342 & 0.5667 & 0.5067 & 0.4533 & 0.4057 & 0.3634 & 0.3256 \\
\hline 24 & 0.8872 & 0.7876 & 0.6995 & 0.6217 & 0.5529 & 0.4919 & 0.4380 & 0.3901 & 0.3477 & 0.3101 \\
\hline 25 & 0.8828 & 0.7798 & 0.6892 & 0.6095 & 0.5394 & 0.4776 & 0.4231 & 0.3751 & 0.3327 & 0.2953 \\
\hline 26 & 0.8784 & 0.7720 & 0.6790 & 0.5976 & 0.5262 & 0.4637 & 0.4088 & 0.3607 & 0.3184 & 0.2812 \\
\hline 27 & 0.8740 & 0.7644 & 0.6690 & 0.5859 & 0.5134 & 0.4502 & 0.3950 & 0.3468 & 0.3047 & 0.2678 \\
\hline 28 & 0.8697 & 0.7568 & 0.6591 & 0.5744 & 0.5009 & 0.4371 & 0.3817 & 0.3335 & 0.2916 & 0.2551 \\
\hline 29 & 0.8653 & 0.7493 & 0.6494 & 0.5631 & 0.4887 & 0.4243 & 0.3687 & 0.3207 & 0.2790 & 0.2429 \\
\hline 30 & 0.8610 & 0.7419 & 0.6398 & 0.5521 & 0.4767 & 0.4120 & 0.3563 & 0.3083 & 0.2670 & 0.2314 \\
\hline 31 & 0.8567 & 0.7346 & 0.6303 & 0.5412 & 0.4651 & 0.4000 & 0.3442 & 0.2965 & 0.2555 & 0.2204 \\
\hline 32 & 0.8525 & 0.7273 & 0.6210 & 0.5306 & 0.4538 & 0.3883 & 0.3326 & 0.2851 & 0.2445 & 0.2099 \\
\hline 33 & 0.8482 & 0.7201 & 0.6118 & 0.5202 & 0.4427 & 0.3770 & 0.3213 & 0.2741 & 0.2340 & 0.1999 \\
\hline 34 & 0.8440 & 0.7130 & 0.6028 & 0.5100 & 0.4319 & 0.3660 & 0.3105 & 0.2636 & 0.2239 & 0.1904 \\
\hline 35 & 0.8398 & 0.7059 & 0.5939 & 0.5000 & 0.4214 & 0.3554 & 0.3000 & 0.2534 & 0.2143 & 0.1813 \\
\hline 36 & 0.8356 & 0.6989 & 0.5851 & 0.4902 & 0.4111 & 0.3450 & 0.2898 & 0.2437 & 0.2050 & 0.1727 \\
\hline 37 & 0.8315 & 0.6920 & 0.5764 & 0.4806 & 0.4011 & 0.3350 & 0.2800 & 0.2343 & 0.1962 & 0.1644 \\
\hline 38 & 0.8274 & 0.6852 & 0.5679 & 0.4712 & 0.3913 & 0.3252 & 0.2706 & 0.2253 & 0.1878 & 0.1566 \\
\hline 39 & 0.8232 & 0.6784 & 0.5595 & 0.4619 & 0.3817 & 0.3158 & 0.2614 & 0.2166 & 0.1797 & 0.1491 \\
\hline 40 & 0.8191 & 0.6717 & 0.5513 & 0.4529 & 0.3724 & 0.3066 & 0.2526 & 0.2083 & 0.1719 & 0.1420 \\
\hline 41 & 0.8151 & 0.6650 & 0.5431 & 0.4440 & 0.3633 & 0.2976 & 0.2440 & 0.2003 & 0.1645 & 0.1353 \\
\hline 42 & 0.8110 & 0.6584 & 0.5351 & 0.4353 & 0.3545 & 0.2890 & 0.2358 & 0.1926 & 0.1574 & 0.1288 \\
\hline 43 & 0.8070 & 0.6519 & 0.5272 & 0.4268 & 0.3458 & 0.2805 & 0.2278 & 0.1852 & 0.1507 & 0.1227 \\
\hline 44 & 0.8030 & 0.6454 & 0.5194 & 0.4184 & 0.3374 & 0.2724 & 0.2201 & 0.1780 & 0.1442 & 0.1169 \\
\hline 45 & 0.7990 & 0.6391 & 0.5117 & 0.4102 & 0.3292 & 0.2644 & 0.2127 & 0.1712 & 0.1380 & 0.1113 \\
\hline 46 & 0.7950 & 0.6327 & 0.5042 & 0.4022 & 0.3211 & 0.2567 & 0.2055 & 0.1646 & 0.1320 & 0.1060 \\
\hline 47 & 0.7910 & 0.6265 & 0.4967 & 0.3943 & 0.3133 & 0.2493 & 0.1985 & 0.1583 & 0.1263 & 0.1009 \\
\hline 48 & 0.7871 & 0.6203 & 0.4894 & 0.3865 & 0.3057 & 0.2420 & 0.1918 & 0.1522 & 0.1209 & 0.0961 \\
\hline 49 & 0.7832 & 0.6141 & 0.4821 & 0.3790 & 0.2982 & 0.2350 & 0.1853 & 0.1463 & 0.1157 & 0.0916 \\
\hline 50 & 0.7793 & 0.6080 & 0.4750 & 0.3715 & 0.2909 & 0.2281 & 0.1791 & 0.1407 & 0.1107 & 0.0872 \\
\hline
\end{tabular}


The Singapore Economic Review (c)World Scientific Publishing Company

Multiplier Table 28

Multipliers for Pecuniary Loss for Term Certain

\begin{tabular}{|c|c|c|c|c|c|c|c|c|c|c|}
\hline \multirow[b]{2}{*}{ Term } & \multicolumn{10}{|c|}{ Multiplier for regular frequent payments for a term certain at rate of return of } \\
\hline & $0.5 \%$ & $1.0 \%$ & $1.5 \%$ & $2.0 \%$ & $2.5 \%$ & $3.0 \%$ & $3.5 \%$ & $4.0 \%$ & $4.5 \%$ & $5.0 \%$ \\
\hline 1 & 1.00 & 1.00 & 0.99 & 0.99 & 0.99 & 0.99 & 0.98 & 0.98 & 0.98 & 0.98 \\
\hline 2 & 1.99 & 1.98 & 1.97 & 1.96 & 1.95 & 1.94 & 1.93 & 1.92 & 1.91 & 1.91 \\
\hline 3 & 2.98 & 2.96 & 2.93 & 2.91 & 2.89 & 2.87 & 2.85 & 2.83 & 2.81 & 2.79 \\
\hline 4 & 3.96 & 3.92 & 3.88 & 3.85 & 3.81 & 3.77 & 3.74 & 3.70 & 3.67 & 3.63 \\
\hline 5 & 4.94 & 4.88 & 4.82 & 4.76 & 4.70 & 4.65 & 4.59 & 4.54 & 4.49 & 4.44 \\
\hline 6 & 5.91 & 5.82 & 5.74 & 5.66 & 5.58 & 5.50 & 5.42 & 5.35 & 5.27 & 5.20 \\
\hline 7 & 6.88 & 6.76 & 6.65 & 6.54 & 6.43 & 6.32 & 6.22 & 6.12 & 6.02 & 5.93 \\
\hline 8 & 7.84 & 7.69 & 7.54 & 7.40 & 7.26 & 7.12 & 6.99 & 6.87 & 6.74 & 6.62 \\
\hline 9 & 8.80 & 8.61 & 8.42 & 8.24 & 8.07 & 7.90 & 7.74 & 7.58 & 7.43 & 7.28 \\
\hline 10 & 9.75 & 9.52 & 9.29 & 9.07 & 8.86 & 8.66 & 8.46 & 8.27 & 8.09 & 7.91 \\
\hline 11 & 10.70 & 10.42 & 10.15 & 9.88 & 9.63 & 9.39 & 9.16 & 8.93 & 8.72 & 8.51 \\
\hline 12 & 11.65 & 11.31 & 10.99 & 10.68 & 10.39 & 10.10 & 9.83 & 9.57 & 9.32 & 9.08 \\
\hline 13 & 12.59 & 12.19 & 11.82 & 11.46 & 11.12 & 10.79 & 10.48 & 10.18 & 9.90 & 9.63 \\
\hline 14 & 13.52 & 13.07 & 12.64 & 12.23 & 11.84 & 11.46 & 11.11 & 10.77 & 10.45 & 10.14 \\
\hline 15 & 14.45 & 13.93 & 13.44 & 12.98 & 12.54 & 12.12 & 11.72 & 11.34 & 10.98 & 10.64 \\
\hline 16 & 15.38 & 14.79 & 14.24 & 13.71 & 13.22 & 12.75 & 12.30 & 11.88 & 11.48 & 11.11 \\
\hline 17 & 16.30 & 15.64 & 15.02 & 14.43 & 13.88 & 13.36 & 12.87 & 12.41 & 11.97 & 11.55 \\
\hline 18 & 17.22 & 16.48 & 15.79 & 15.14 & 14.53 & 13.96 & 13.42 & 12.91 & 12.43 & 11.98 \\
\hline 19 & 18.13 & 17.31 & 16.55 & 15.83 & 15.17 & 14.54 & 13.95 & 13.39 & 12.87 & 12.38 \\
\hline 20 & 19.03 & 18.14 & 17.30 & 16.51 & 15.78 & 15.10 & 14.46 & 13.86 & 13.30 & 12.77 \\
\hline 21 & 19.94 & 18.95 & 18.03 & 17.18 & 16.39 & 15.65 & 14.95 & 14.31 & 13.70 & 13.14 \\
\hline 22 & 20.84 & 19.76 & 18.76 & 17.83 & 16.97 & 16.17 & 15.43 & 14.74 & 14.09 & 13.49 \\
\hline 23 & 21.73 & 20.56 & 19.48 & 18.47 & 17.55 & 16.69 & 15.89 & 15.15 & 14.46 & 13.82 \\
\hline 24 & 22.62 & 21.35 & 20.18 & 19.10 & 18.11 & 17.19 & 16.34 & 15.55 & 14.82 & 14.14 \\
\hline 25 & 23.50 & 22.13 & 20.87 & 19.72 & 18.65 & 17.67 & 16.77 & 15.93 & 15.16 & 14.44 \\
\hline 26 & 24.38 & 22.91 & 21.56 & 20.32 & 19.19 & 18.14 & 17.18 & 16.30 & 15.48 & 14.73 \\
\hline 27 & 25.26 & 23.68 & 22.23 & 20.91 & 19.71 & 18.60 & 17.59 & 16.65 & 15.80 & 15.01 \\
\hline 28 & 26.13 & 24.44 & 22.90 & 21.49 & 20.21 & 19.04 & 17.97 & 16.99 & 16.09 & 15.27 \\
\hline 29 & 27.00 & 25.19 & 23.55 & 22.06 & 20.71 & 19.47 & 18.35 & 17.32 & 16.38 & 15.52 \\
\hline 30 & 27.86 & 25.94 & 24.20 & 22.62 & 21.19 & 19.89 & 18.71 & 17.64 & 16.65 & 15.75 \\
\hline 31 & 28.72 & 26.67 & 24.83 & 23.17 & 21.66 & 20.30 & 19.06 & 17.94 & 16.91 & 15.98 \\
\hline 32 & 29.58 & 27.41 & 25.46 & 23.70 & 22.12 & 20.69 & 19.40 & 18.23 & 17.16 & 16.19 \\
\hline 33 & 30.43 & 28.13 & 26.07 & 24.23 & 22.57 & 21.08 & 19.73 & 18.51 & 17.40 & 16.40 \\
\hline 34 & 31.27 & 28.85 & 26.68 & 24.74 & 23.01 & 21.45 & 20.04 & 18.78 & 17.63 & 16.59 \\
\hline 35 & 32.12 & 29.56 & 27.28 & 25.25 & 23.43 & 21.81 & 20.35 & 19.04 & 17.85 & 16.78 \\
\hline 36 & 32.95 & 30.26 & 27.87 & 25.74 & 23.85 & 22.16 & 20.64 & 19.28 & 18.06 & 16.96 \\
\hline 37 & 33.79 & 30.95 & 28.45 & 26.23 & 24.26 & 22.50 & 20.93 & 19.52 & 18.26 & 17.13 \\
\hline 38 & 34.62 & 31.64 & 29.02 & 26.70 & 24.65 & 22.83 & 21.20 & 19.75 & 18.45 & 17.29 \\
\hline 39 & 35.44 & 32.32 & 29.58 & 27.17 & 25.04 & 23.15 & 21.47 & 19.97 & 18.64 & 17.44 \\
\hline 40 & 36.26 & 33.00 & 30.14 & 27.63 & 25.42 & 23.46 & 21.73 & 20.19 & 18.81 & 17.58 \\
\hline 41 & 37.08 & 33.67 & 30.69 & 28.08 & 25.78 & 23.76 & 21.97 & 20.39 & 18.98 & 17.72 \\
\hline 42 & 37.89 & 34.33 & 31.23 & 28.52 & 26.14 & 24.06 & 22.21 & 20.59 & 19.14 & 17.86 \\
\hline 43 & 38.70 & 34.98 & 31.76 & 28.95 & 26.49 & 24.34 & 22.45 & 20.78 & 19.30 & 17.98 \\
\hline 44 & 39.51 & 35.63 & 32.28 & 29.37 & 26.83 & 24.62 & 22.67 & 20.96 & 19.44 & 18.10 \\
\hline 45 & 40.31 & 36.27 & 32.80 & 29.78 & 27.17 & 24.88 & 22.89 & 21.13 & 19.58 & 18.21 \\
\hline 46 & 41.10 & 36.91 & 33.30 & 30.19 & 27.49 & 25.15 & 23.10 & 21.30 & 19.72 & 18.32 \\
\hline 47 & 41.90 & 37.54 & 33.80 & 30.59 & 27.81 & 25.40 & 23.30 & 21.46 & 19.85 & 18.43 \\
\hline 48 & 42.69 & 38.16 & 34.30 & 30.98 & 28.12 & 25.64 & 23.49 & 21.62 & 19.97 & 18.53 \\
\hline 49 & 43.47 & 38.78 & 34.78 & 31.36 & 28.42 & 25.88 & 23.68 & 21.77 & 20.09 & 18.62 \\
\hline 50 & 44.25 & 39.39 & 35.26 & 31.74 & 28.72 & 26.11 & 23.86 & 21.91 & 20.20 & 18.71 \\
\hline
\end{tabular}


The Singapore Economic Review

(c)World Scientific Publishing Company

Accepted 30 March 2010

Accepted Paper

\section{References}

Akaike, H. (1974). A New Look at the Statistical Model Identification. IEEE Transactions on Automatic Control, AC-19: 716-723.

Boot, J.C.G. and J.H.C. Lisman (1967). Further Methods of Derivation of Quarterly Figures from Annual Data. Applied Statistics, 16, 65-75.

Box, G.E.P. and G.M. Jenkins (1976). Time Series Analysis Forecasting and Control. 2nd ed., San Francisco: Holden-Day.

Collins, L., C. G. J. Morse, D. McClean, A. Briggs, J. Harris and C. McLachlan (2008). Dicey, Morris \& Collins on the Conflict of Laws: Mainwork \& Supplement. 14th Edition, London: Sweet \& Maxwell.

Brouhns, N., M. Denuit and J.K. Vermunt (2002). A Poisson Log-bilinear Regression Approach to the Construction of Projected Lifetables. Insurance: Mathematics and Economics, 31, 373-393.

Brouhns, N., M. Denuit and I.V. Keilegom (2005). Bootstrapping the Poisson Log-bilinear Model for Mortality Forecasting. Scandinavian Actuarial Journal, 3, 212-224.

Butt, Z., S. Haberman, R. Verrall and V. Wass (2008). Calculating Compensation for Loss of Future Earnings: Estimating and Using Work Life Expectancy. Journal of the Royal Statistical Society Series A, 171, 763-805.

Chan, W.S. and F.W.H. Chan (2000). Lai Wee Lian Revisited - Should Actuarial Tables be Used for the Assessment of Damages in Personal Injury Litigation in Singapore? Singapore Journal of Legal Studies, 5, 364-378.

Chia, N.C. and A.K.C. Tsui (2003). Life Annuities of Compulsory Savings and Income Adequacy of the Elderly in Singapore. Journal of Pension Economics and Finance, 2, 41-65.

Coale, A. and E. Kisker (1990). Defects in Data on Old-age Mortality in the United States: New Procedures for Calculating Mortality Schedules and Life Tables at the Highest Ages. Asian and Pacific Population Forum, 4, 1-31.

Cossette, H., A. Delwarde, M. Denuit, F. Guillot and E. Marceau (2007). Pension Plan Valuation and Mortality Projection: A Case Study with Mortality Data. North American Actuarial Journal 11, 1-34.

Czado, C., A. Delwarde, and M. Denuit (2005). Bayesian Poisson Log-bilinear Mortality Projections. Insurance: Mathematics and Economics, 36, 260-284.

Fisher, D. (2001). Intermediate Macroeconomics: A Statistical Approach. Singapore: World Scientific.

Fisher, I. (1930). The Theory of Interest. New York: Macmillan.

Haberman, S. and D.S.F. Bloomfield (1990). Work Time Loss to Sickness, Unemployment and Stoppages: Measurement and Application. Journal of the Institute of Actuaries, $117,533-595$. 
Hermer, R. and J. Pickering (2002). Future Loss Multipliers: The Quantification of Damages for Catastrophic Injuries. Journal of Personal Injury Law, 4, 377-383.

Hogg, R. (2002). Multipliers - The Discount Rate. Journal of Personal Injury Law, 1, 46-48.

Hogg, R. and D. Kemp (1999). Assessing Future Pecuniary Loss Using the 'Ogden Tables'. Journal of Personal Injury Litigation, 9, 42-48.

Human Mortality Database. University of California, Berkeley (USA), and Max Planck Institute of Demographic Research (Germany). Available at www.mortality.org or www.humanmortality.de (data downloaded on 15 March 2008).

Kemp, D. and R. Hogg (2000). How to Determine Multipliers in Assessing Damages under the Fatal Accident Acts, Using Revised 'Ogden Tables'. Journal of Personal Injury Law, $2 / 3,142-155$.

Koissi, M.C., A.F. Shapiro and G. Hognas (2006). Evaluating and Extending the Lee-Carter Model for Mortality Forecasting: Bootstrap Confidence Interval. Insurance: Mathematics and Economics, 38, 1-20.

Langstaff, B. (2003). Structured Settlements: Past, Present and Future. Journal of Personal Injury Law, 217/282, 237-255.

Lee, R.D. (2000). The Lee-Carter Method for Forecasting Mortality, with Various Extensions and Applications. North American Actuarial Journal, 4, 80-91.

Lee, R.D. and L. Carter (1992). Modeling and Forecasting U.S. Mortality. Journal of the American Statistical Association, 87, 659-671.

Lewis, R. (1993). The Merits of a Structured Settlement: The Plaintif's Perspective Oxford Journal of Legal Studies, 13, 530-547.

Lewis, R. (2006). The Politics and Economics of Tort Law: Judicially Imposed Periodical Payments of Damages. Modern Law Review, 69, 418-442.

Li, S.H. and W.S. Chan (2004). Estimation of Complete Period Life Tables for Singaporeans. Journal of Actuarial Practice, 11, 129-146.

Luckett, N. and J. Craner (1994). Multiplers: Are the Courts Being Fair to Plaintiffs? Journal of Personal Injury Litigation, 4, 139-146.

Lyons, M. (2002) Personal Injuries - Brain Damage - Care Expenses. Journal of Personal Injury Law, 3, 332-333.

Ng, S. and P. Perron (1995). Unit Root Test in ARMA Models with Data Dependent Methods for the Selection of the Truncation Lag, Journal of the American Statistical Association, 90, 268-281.

Office for National Statistics (1997). English Life Tables No. 15. London: The Stationery Office.

Renshaw, A.E. and S. Haberman (2003a). LeeCarter Mortality Forecasting with Age-Specific Enhancement. Insurance: Mathematics and Economics, 33, 255-272. 
Renshaw, A.E. and S. Haberman (2003b). On the Forecasting of Mortality Reduction Factors. Insurance: Mathematics and Economics, 32, 379-401.

Renshaw, A.E. and S. Haberman (2006). A Cohort-based Extension to the Lee-Carter Model for Mortality Reduction Factors. Insurance: Mathematics and Economics, 38, 556-570.

Renshaw, A.E. and S. Haberman (2008). On Simulation-Based Approaches to Risk Measurement in Mortality with Specific Reference to Poisson LeeCarter Modelling. Insurance: Mathematics and Economics, 42, 797-816.

Schwarz, G. (1978). Estimating the Dimension of a Model. Annals of Statistics, 6, 461-464.

Thomas, L.B. (1999). Survey Measures of Expected U.S. Inflation. Journal of Economic Perspectives, 13, 125-144.

Tuljapurkar, S., N. Li and C. Boe (2000). A Universal Pattern of Mortality Decline in the G7 Countries. Nature, 405, 789-792.

Wilkie, A.D. (1995). More on a Stochastic Asset Model for Actuarial Use. British Actuarial Journal, 1, 777-964.

Wilmoth, J.R. (1993). Computational Methods for Fitting and Extrapolating the Lee-Carter Model of Mortality Change. Technical report. Department of Demography. University of California, Berkeley. 